\title{
Management of cytoskeleton architecture by molecular chaperones and immunophilins
}

\author{
Héctor R. Quintáa ${ }^{\text {, Natalia M. Galigniana }}{ }^{\mathrm{a}}$, Alejandra G. Erlejman ${ }^{\mathrm{b}}$, Mariana Lagadaria ${ }^{\mathrm{a}}$, \\ Graciela Piwien Pilipuk ${ }^{a}$, and Mario D. Galigniana ${ }^{a, b,{ }^{*}}$ \\ anstituto de Biología y Medicina Experimental-CONICET, Vuelta de Obligado 2490, Buenos \\ Aires (C1428ADN), Argentina. \\ bDepartamento de Química Biológica, Facultad de Ciencias Exactas y Naturales, Ciudad \\ Universitaria, Universidad de Buenos Aires, Buenos Aires (C1428EGA), Argentina.
}

\begin{abstract}
Cytoskeletal structure is continually remodeled to accommodate normal cell growth and to respond to pathophysiological cues. As a consequence, several cytoskeleton-interacting proteins become involved in a variety of cellular processes such as cell growth and division, cell movement, vesicle transportation, cellular organelle location and function, localization and distribution of membrane receptors, and cell-cell communication. Molecular chaperones and immunophilins are counted among the most important proteins that interact closely with the cytoskeleton network, in particular with microtubules and microtubule-associated factors. In several situations, heat-shock proteins and immunophilins work together as a functionally active heterocomplex, although both types of proteins also show independent actions. In circumstances where homeostasis is affected by environmental stresses or due to genetic alterations, chaperone proteins help to stabilize the system. Molecular chaperones facilitate the assembly, disassembly and/or folding/refolding of cytoskeletal proteins, so they prevent aberrant protein aggregation. Nonetheless, the roles of heat-shock proteins and immunophilins are not limited to solve abnormal situations, but they also have an active participation during the normal differentiation process of the cell and are key factors for many structural and functional rearrangements during this course of action. Cytoskeleton modifications leading to altered localization of nuclear factors may result in loss- or gain-of-function of such factors, which affects the cell cycle and cell development. Therefore, cytoskeletal components are attractive therapeutic targets, particularly microtubules, to prevent pathological situations such as rapidly dividing tumour cells or to favor the process of cell differentiation in other cases. In this review we will address some classical and novel aspects of key regulatory functions of heat-shock proteins and immunophilins as housekeeping factors of the cytoskeletal network.
\end{abstract}

\section{Keywords}

Heat-shock protein; Microtubule; Microfilament; Intermediate Filament; Stress; Folding

(C) 2011 Elsevier Inc. All rights reserved.

*Corresponding author: Tel.:+54-11-4783-2869; Fax: +54-11-4786-2564; mgali@qb.fcen.uba.ar (M.D.Galigniana).

Publisher's Disclaimer: This is a PDF file of an unedited manuscript that has been accepted for publication. As a service to our customers we are providing this early version of the manuscript. The manuscript will undergo copyediting, typesetting, and review of the resulting proof before it is published in its final citable form. Please note that during the production process errors may be discovered which could affect the content, and all legal disclaimers that apply to the journal pertain. 
Cytoskeleton is the basic scaffold of the cell in which other subcellular components are spatially arranged, such that they are able to communicate efficiently between the internal and external environments of the cell. Although the folding system of this assortment of filamentous and tubular polymers composed of microtubules, microfilaments and intermediate filaments was discovered more than two decades ago, our understanding of the complex quality control pathway of these structures is still poorly understood and there are many unanswered questions that remain to be elucidated. The cytoskeleton is incomplete without its associated proteins. The proteins known to closely communicate with the cytoskeletal network include molecular chaperones that appear to protect the cytoskeleton in circumstances where cytoskeletal homeostasis is affected.

Molecular chaperones were first described as preferentially synthesized factors in organisms exposed to heat or other physiological stresses. In an attempt to restore cellular function under these conditions, some molecular chaperones prevent denaturation of proteins while others may dissociate protein aggregates, refold monomers, oligomers or simply direct them to their proteolytic cleavage. Nevertheless, chaperones are also synthesized constitutively and, under normal conditions, they also exert cardinal functions in the organization of the structures of the cell as well as in the functional efficiency of several signaling cascades. In this review it is analyzed the relationship between molecular chaperones and the organization of the structure and function of the cytoskeleton.

\section{The cytoskeleton}

The cytoskeleton constitutes the structural support of the living matter. It also plays key functional roles in the life time of the cells and during their replication. The cytoskeleton is present in all eukaryotic cells and was once thought to be an exclusive structure of eukaryotes, but homologues of the major scaffold proteins of the eukaryotic cytoskeleton have also been found in prokaryotes [1,2]. The cytoskeleton is a dynamic three dimensional filamentous structure that fills the cytoplasm maintaining the cell shape, enables the cell to move, and plays cardinal roles in the intracellular transport of vesicles, organelles and soluble proteins, during the cell division, the segregation of chromosomes, maintenance of proper cell shape, cell polarity and assembly of intracellular organelle-like structures. The three types of cytoskeletal elements that have been characterized in eukaryotic cells are tubulins, actins, and intermediate filaments (IFs).

\subsection{Tubulin}

Tubulin forms microtubules of about $25 \mathrm{~nm}$ in diameter consisting of straight 13 protofilaments that assemble into hollow tubules through lateral contacts to both sides of the protofilaments [3]. The cylinder yields a helical arrangement in which each turn of the helix spans three tubulin monomers (e.g., $\alpha, \beta, \alpha$ ). This generates a seam in the microtubule wall where, instead of the predominant $\alpha \alpha$ and $\beta \beta$ lateral contacts, subunits are laterally adjacent to $\beta$ subunits. Microtubules are organized from the minus end (in close vicinity with the centrosome) and extend through association of GTP-bound $\alpha$-tubulin and $\beta$-tubulin heterodimers onto the plus end, which faces the cell periphery. The dimers are released from the minus end after hydrolysis, which destabilizes the intrafilament contacts. However, microtubules can rapidly release dimers from both ends and thus shrink, a stochastic event called catastrophic collapse, giving rise to dynamic instability of the filaments. Thus, tubulin filaments are highly dynamic elements within the cells. $\gamma$-Tubulin, which is homologous to $\alpha$ and $\beta$ tubulins, nucleates microtubule assembly within the centrosome in a structure called microtubule organizing center (or MTOC). Around 12 to14 copies of $\gamma$ tubulin associate in the complex with other proteins called GRIPS (for gamma-ring proteins), this complex being capped at one end and thought to be the minus end terminal. Microtubule polymerization at this end is inhibited, and the GRIP proteins of the cap may be 
involved in mediating binding to the centrosome. Phosphorylation of a conserved tyrosine residue of $\gamma$-tubulin has been shown to regulate microtubule nucleation [4]. In vertebrate cells, but not in plants, a specific microtubule-based organelle is embedded within the organizing center, the centriole.

Microtubules set up the tracks of the mitotic spindle apparatus that are used to segregate chromosomes during mitosis and meiosis through dedicated motor proteins. Microtubules are key actors in organizing the spatial distribution of organelles in interphase cells, are stable components of cilia and flagella, and also serve to provide tracks for the transport of intracellular vesicles and other cargoes that are moved through cells by motor proteins such as dynein and kinesin, which show predominant retrograde and anterograde direction of movement on microtubules.

\subsection{Actin}

Actin forms a two-stranded, right-handed helical filament of about $7 \mathrm{~nm}$ in diameter with an axial rise of $5.4 \mathrm{~nm}$ per monomer that has a plus-/minus-end polarity and is also dynamic [5]. Owing to filament asymmetry, ATP-bound actin adds to the plus end (often called the barbed end) much faster than it does to the minus end (also called the pointed end). ATPase activity leads to conversion to ADP-actin within the filament, and ADP-actin is released at the minus end. This process is called tread-milling and leads to a net polymerization at one end and depolymerization at the other end. Thus, while the center of the filament (and each subunit) remains stationary, the tip of the filament can push objects by limiting them in their diffusion, such that they can diffuse only in the direction of the extended filament. Actin polymerization is required for cell movement via extension of pseudopods, where other additional proteins induce branching of actin filaments generating a network that pushes against the leading edge of the membrane in a brush-like manner [6]. Actin is also required for the movement of some types of vesicles through cells [7].

In addition, actin is a contractile protein and one of the most abundant proteins in cells. In muscle cells, the association of microfilaments with myosin is responsible for muscle contraction. Microfilaments can also carry out cellular movements including gliding, contraction, and cytokinesis. They are mostly concentrated just beneath the plasma membrane, as they keep cellular shape, form cytoplasmatic protuberances such as pseudopodia and microvilli, and participate in cell-to-cell or cell-to-matrix junctions and in the transduction of signals. Recently, it was demonstrated the existence of a subset of actomyosin fibers that form a perinuclear actin cap, a cytoskeletal structure that tightly wraps around the nucleus [8]. Fibers in the actin cap are distinct from the conventional actin fibers at the basal and dorsal surfaces of adherent cells in their organization, dynamics, response to cytoskeletal pharmacological treatments and biochemical stimuli, and response to disease-associated mutations of lamins $\mathrm{A} / \mathrm{C}$. The perinuclear actin cap precisely shapes the nucleus in interphase cells and is a mediator of microenvironment mechanosensing and mechanotransduction, as well as a regulator of cell motility, polarization and differentiation $[8,9]$.

\subsection{Intermediate filaments}

IFs are composed of extended coiled-coil proteins that assemble into rigid sheets. IFs form 8- to 10-nm-thick cytoskeletal elements that provide internal mechanical support for the cell and position different organelles [10,11]. They form a large superfamily of proteins containing 73 gene products [12] that are expressed in tissue-, cell-, differentiation-, and development-dependent manners, and are related to more than 90 human pathologies (www.interfil.org). Different kinds of IFs share similar basic characteristics. IFs provide the tensile strength of a cell and determine its internal structure; for example, they are structural 
components of the nuclear envelope and of the sarcomeres and participate in some cell-cell and cell-matrix junctions [13].

IFs are classified in six types. Type I and II are acidic and basic keratins, respectively, and form the cytoskeleton of epithelial tissues, skin-hair, nails, and horns. Many intermediate filaments are made of vimentins, a type III IF that is highly abundant in mesenchymal cells, such that it is often used as marker of mesenchymally-derived cells or cells undergoing an epithelial-to-mesenchymal transition during both normal development and metastatic progression [14]. Also, vimentin is found to control the transport of low-density lipoproteinderived cholesterol from lysosomes to the esterification sites [15]. The type IV family of IFs shows neurofilaments as filament archetype. Neurofilaments are found in high concentrations in the axons of vertebrate neurons associated to some IFs that copurify with them such as $\alpha$-internexin. Some muscle-specific filaments such as syncoilin and synemins are also clustered into this type of IF. Type V filaments are the lamins, fibrous proteins that give structural support to the nuclear envelope. Finally, type VI IF comprise nestins, whose expression has been extensively used as a marker for central nervous system progenitor cells based on observations indicating a correlation between nestin expression and this cell type in vivo [16]. Its expression is usually transient and upon differentiation, nestin becomes downregulated and is replaced by tissue-specific IFs, e.g. neurofilaments and glial fibrillary acidic protein (GFAP) during neurogenesis and gliogenesis.

IFs are much less conserved in sequence than are tubulins or actin, because different sequences can make up coiled-coil motifs. IFs display a tripartite structure consisting of an $\alpha$-helical central rod flanked by non-helical head and tail domains, and assemble to give rise to nuclear (lamins) or to different cytoplasmic IF networks such as keratins, vimentin, neurofilaments, peripherin, desmin, and GFAP [17-19]. IFs are regulated by both posttranslational modifications and through interactions with multiple IF-associated signaling cascade proteins such as 14-3-3 proteins, apoptosis-related proteins, kinases and phosphatases [20,21], all of them being processes that may affect from IF solubility to sensitivity to be degraded by caspases or proteosomal degradation. Unique functional roles for IFs also include protection from mechanical stress sharing cytoprotective roles with associated heat-shock proteins to inhibit apoptosis, regulate organelle homeostasis, and scaffolding [19].

\subsection{Prokaryotic cytoskeleton}

Before the 90's, the cytoskeleton was thought to have evolved only in eukaryotes. However, cytological techniques developed for eukaryotic cells were adapted and used for the study of the cellular organization of bacteria and archaea, revealing that these organisms also contain a number of subcellular counterparts of actin, tubulin, and IF proteins [2, 22-24]. FtsZ was the first of these proteins to be identified. Like tubulin, FtsZ forms filaments in the presence of GTP, although the filaments do not group into tubules. During cell division, FtsZ moves to the division site and recruits other proteins required to generate a new cell wall between the dividing cells. On the other hand, MreB is considered the prokaryotic actin-like protein. As such, it is involved in maintaining cell shape. Non-spherical bacteria also encode other actin-like proteins that form a helical network beneath the cell membrane, which in turn guides the proteins required for the synthesis of a new cell wall. Other actin-like protein is ParM, whose filaments participate in the division of plasmidic DNA into the daughter cells by a mechanism similar to that used by microtubules during eukaryotic mitosis. Finally, crescentin is a bacterial counterpart related to IFs of eukaryotic cells and is involved in maintaining cell shape.

Cytoskeleton proteins of both eukaryotic and prokaryotic cells require the assistance of associated factors for the maintenance of their structures and functions. In this regard, 
molecular chaperones are essential for this process. This is not surprising if three essential facts are considered: a) there is a structural similarity between actins and the Hsp70 class of molecular chaperones [25, 26]; b) heat-shock has deleterious effects on the internal organization of the cell beyond the unfolding of individual proteins and, especially in eukaryotes, one of the major damages observed in response to stress conditions are defects of the cytoskeleton and loss of the proper localization of organelles and breakdown of intracellular transport processes; and c) prokaryotic heat-shock proteins have been preserved during the evolution and show high structural homology with their eukaryotic patterns to the point that most of them can be functionally exchanged.

\section{Molecular chaperones}

Socially speaking, the term chaperone refers to a person (as a matron) who used to accompany young unmarried women in public or supervise young people at a social gathering to ensure proper behavior. By analogy, those proteins that assist others in their proper folding and biological functions are referred to as chaperones (e.g. Hsp90 or Hsp70). The term 'molecular chaperone' was first used to describe the ability of nucleoplasmin to prevent the aggregation of histones with DNA during the assembly of nucleosomes, and was extended to describe proteins that mediated the post-translational assembly of protein complexes (see an appealing background in Ellis review [27]). The term co-chaperone, sometimes wrongly employed as synonym of chaperone, refers to proteins that assist chaperones or are associated to them favoring the properties of the client-protein (e.g. p23 or FKBP52). Normally, co-chaperones are non-client-binding partners, although they may themselves have chaperone activity as well. Chaperonines are protein complexes that assist the folding of nascent non-native polypeptides into their native functional state (e.g. Hsp10/ GroES, TRiC/CCT). All these proteins, chaperones, co-chaperones and chaperonines, belong to a larger class of molecules that assist protein folding, the molecular chaperones, whose major function is to prevent both newly synthesized polypeptide chains and assembled subunits from aggregating into nonfunctional structures. It is for this reason that many chaperones, but by no means all, are also heat-shock proteins (Hsp) since the tendency to aggregate increases as proteins are denatured by stress.

\subsection{Heat-shock proteins}

The term "heat-shock protein" stems from the original observation that heat-stress greatly enhances the production of a specific class of proteins, subsequently identified as molecular chaperones. The Hsp family comprises five major and broadly conserved subfamiliesHsp100s, Hsp90s, Hsp70s, Hsp60s, and small heat shock proteins (sHsps). Several other heat-inducible molecular chaperones, like Hsp33 [28] are also part of the family, but since they are not ubiquitous, they were not included in a separate subfamily. Because the stability of cellular proteins is relatively low and aggregation competes with their efficient folding, even at physiological temperatures, there is a constant need for chaperone assistance during de novo protein folding and refolding of non-native polypeptide chains [29, 30]. What discriminates a native protein from its non-native unfolded (partially or globally) counterpart is the exposure of hydrophobic residues, which are recognized by molecular chaperones. Normally, binding to hydrophobic patches, specific peptide sequences, or structural elements of the non-native protein takes place to protect these proteins from aggregation and degradation. Generally, molecular chaperones do not contribute to the structural information for protein folding, but prevent those unwanted intermolecular interactions. Chaperones do this through controlled binding and release of non-native proteins, which is usually accomplished by a change of the affinity of the chaperone for its client substrate. This exchange between two or more affinity states is controlled by the binding to the chaperone and/or subsequent hydrolysis of ATP molecules, with the sole exception of sHsps. The latter chaperones are optimal for an efficient first line of defense. This is why these low molecular 
weight chaperones are also known as holdases. On the other hand, the foldases come in stress-induced and constitutively expressed versions (e.g., Hsp70 versus Hsc70).

2.1.1. Hsp90-Hsp90 is the major soluble cytosolic protein that is expressed under both normal ( $2-3 \%$ of the total) and stressful conditions $(6-10 \%$ of the total) [30-33]. In mammals there are two isoforms, Hsp90 $\alpha$ and $\mathrm{Hsp} 90 \beta$, encoded by separate genes and usually forming homodimers [34]. It is primarily a cytosolic protein, but a small portion rapidly accumulates in cell nuclei upon stress. It is a phosphoprotein containing two to three phosphate molecules per monomer, which is thought that enhances its function. Hsp90 is evolutionarily conserved among species, and is proven essential for cell survival. Its contribution to various cellular processes, including signal transduction, protein folding and degradation, and morphological evolution, has been extensively studied and reviewed [31, 35-39]. Its analogues include Grp94 in the endoplasmic reticulum and Hsp75/TRAP1 in the mitochondrial matrix.

Hsp90 displays a relatively weak ATPase and chaperoning activity, i.e., prevention of aggregation of unfolded polypeptides and assistance in their refolding. It is more selective than other chaperones and chaperonines for the recognition of its substrates and shows low affinity for unfolded proteins. Actually, its principal role in the cell is to provide biological activity to properly folded client proteins with a preserved tertiary structure and functions as a delicate and refined sensor of protein function rather than a gross folding factor. In particular, the cooperation of Hsp90 with other chaperones such as the Hsp70/Hsp40 complex and cochaperones such as p23 and immunophilins (IMMs) makes a vital contribution to the maturation of signal-transduction proteins such as steroid receptors and protein-kinases [36]. Thus, highly orchestrated interactions between the immature, low affinity steroid receptor protein and the Hsp90-based heterocomplex is required to shape the mature and biologically active forms of the receptors that trigger steroid signaling [36, 40]. Importantly, the Hsp90•FKBP52 complex is responsible for the retrotransport of soluble factors using microtubules as cellular tracts [33, 41, 42]. This interaction is possible thanks to the presence of a TPR-acceptor site in the Hsp90 dimer.

In addition to TPR-domain co-chaperones, Hsp90 also shows other co-chaperone binding site for the small acidic cochaperone $\mathrm{p} 23$. It comprises the N-terminal ATP-binding site plus a downstream domain, all in an Hsp90-dimer arrangement.[43]. It enters at a late stage of the cycle and enhances the maturation of client proteins stabilizing their interactions with Hsp90. Dimers of Hsp90 are in dyamic equilibrium between two states, the ADP-bound isoform and the ATP-bound isoform (Fig.1). The ADP-bound Hsp90 shows higher affinity for a TPR-domain cochaperone named Hop (heat-shock organizing protein) that brings together Hsp70 and Hsp90 (this is the genesis of its name) and also influences the functioning of Hsp90. Hop binding to Hsp90 blocks ATP binding and the ATPase activity of the chaperone, and this inhibits very effectively the binding of the cochaperone p23 [44, 45]. Such ADP-bound conformation of Hsp90 is favored by the Hsp90 disrupting agent geldanamycin, which shows high affinity by the nucleotide binding site of the chaperone. Geldanamycin prevents the entry of both p23 and TPR-domain immunophilins to the complex, and consequently, inhibits the major chaperoning activity of Hsp90. On the other hand, when ADP is exchanged by ATP, this ATP-bound isoform of Hsp90 is stabilized by p23 binding and other TPR factors such as IMMs are efficiently recruited (Fig.1). The ATPbound isoform of Hsp90 is a better modulator of the biological activity of client factors. In this regard, it appears that p23 binding to Hsp90 changes the environment of the ATP bound to Hsp90 and prevents the intrinsic ATPase activity of the chaperone [46], which in turn affects the biological activity of the Hsp90-bound client factor. 
In addition to this stabilizing function, p23 also shows independent functions, the most surprising being its cytosolic activity of glutathione-dependent prostaglandin E2 synthase [47]. It has been shown in mice that p23 is not essential for prenatal development and morphogenesis, but it is absolutely necessary for perinatal survival [48]. Thus, $p 23^{-/-}$mice show an incomplete skin barrier, the lungs display underdeveloped airspaces and substantially reduced expression of surfactant genes. This correlates with the known function of glucocorticoids in promoting lung maturation and the role of p23 in the assembly of a hormone-responsive GR $\cdot H s p 90$ complex. Thus, p23 contributes a non-redundant, temporally restricted, and tissue-specific function during mouse development.

2.1.2. Hsp70-The Hsp70 subfamily of chaperones is the most conserved of the entire family. Human Hsp70 also shows two isoforms - Hsp72 (gene name HspAl), which is inducible upon the onset of stressing conditions, and the other, more properly named Hsp73 or Hsc70 (heat-shock cognate-70), is constitutive (gene name HspA8). Human Hsc70 has $85 \%$ identity with human Hsp72. Unlike canonical heat-shock proteins that prevent the aggregation of unfolding proteins and can refold aggregated proteins, Hsc70 is constitutively expressed and performs functions related to normal cellular processes. Hsc70 was placed in the heat-shock protein family due to homology with other heat-shock proteins, but the biological functions of both isoforms differ. A good example is the case of the murine epithelial sodium channel, whose surface expression and function are decreased by Hsc70, whereas both properties are favored by Hsp70 [49].

The activity of Hsp70s is regulated by cofactors, the most important being Hsp40. The Jdomains of these proteins interact with the ATPase domain of Hsp70 and stimulate the hydrolysis of bound ATP [50]. The release of nucleotide and substrate is further accelerated by nucleotide-exchange factors. It was originally shown that Hsp70 and Hsp40 are required for ubiquitin-dependent degradation of short-lived and abnormal proteins [51]. The overexpression of the Hsp70/Hsp40 complex decreases the level of abnormal proteins and improves viability in cellular models of certain neurodegenerative diseases characterized by the accumulation of aberrant proteins, such as Parkinson's disease, Huntington's disease, and spinal and bulbar muscular atrophy [52-56].

It was originally thought that both Hsp90 and Hsp70 worked to promote refolding of proteins that aggregated in stressed cells, but it has subsequently become clear that it is Hsp70 the chaperone that focuses unfolded proteins on proteasomal degradation, whereas Hsp90 shows a protective role, as it is suggested by the fact that its inhibition with geldanamycin promotes protein degradation.

2.1.3. TPR-Domain Immunophilins-Immunophilins (IMMs) comprise a family of intracellular proteins with peptidyl-prolyl-cis/trans-isomerase (PPIase) activity, i.e., cis $\leftrightarrow$ trans interconvertion of Xaa-Pro bonds. IMMs are classified by their ability to bind immunosuppressant drugs -cyclophilins bind cyclosporine A, and FKBPs (FK506-binding proteins) bind FK506 [36, 57]. The signature domain of the family is the PPIase domain. Only the low molecular weight immunophilins FKBP12 and CyPA are related to the immunosuppressive effect when the drug•IMM complex inhibits the Ser/Thr-phosphatase activity of PP2B/calcineurin. High molecular weight IMMs have three additional domains the nucleotide-binding domain, where ATP binds, the calmodulin-binding domain, a poorly characterized domain able to interact with calmodulin, and TPR domains, through which they bind to Hsp90 [58]. See Fig.3A in advance for a comparative scheme of the structures of FKBP51 and FKBP52 (the functional properties will be addressed later on in the topic 4). TPR-domain IMMs are abundant and ubiquitous proteins that were first discovered associated to steroid receptors. To date, the biological function of these proteins is poorly understood. In 2001, it was reported that the dynein/dynactin complex binds to FKBP52 
favoring the glucocorticoid retrotransport [59]. Complexes of IMMs and motor proteins have also been related to other proteins' trafficking, such as mineralocorticoid receptor [60], androgen receptor [61], p53 [62], the AIF/Rac3 complex [63], adeno-associated virus 2 [64], etc., suggesting that factors able to interact with the hsp90•FKBP52 complex could share a similar molecular machinery of movement. The low molecular weight IMM CyPA also interacts with dyenin and it is thought to participate in viral particles transport [65]. The biological function on protein trafficking of IMMs associated to heat-shock proteins is not limited to the cytoplasm. Once the cargo has reached the nuclear envelope using microtubules as molecular tracks, it must traverse the nuclear pore. The Hsp90 complex, including FKBP52 (but not the highly homologous partner FKBP51), interacts with the nuclear import machinery of nucleoporins and importins facilitating the nuclear import of cargoes [32].

Most TPR-domain IMMs can interact with motor proteins [66], but this property or the ability of favoring the retrotransport of proteins is also shared by some low molecular weight cyclophilins $[65,67]$. Nonetheless, the best characterized are the TPR-domain IMMs because they were found associated to the steroid receptor $\bullet \mathrm{Hsp} 90$ complex, in particular FKBP52 and FKBP51. These two IMMs show 60\% identity and 75\% similarity [68]. They bind hsp90 via TPR domains, contain an active PPIase domain, and adopt similar conformations according to X-ray crystallography images [69, 70]. Nonetheless, their functions differ drastically. FKBP52 is a positive regulator of the activity of the glucocorticoid receptor, progesterone receptor and androgen receptor, whereas FKBP51 has generally been regarded to be a negative regulator of steroid receptor activity as its overexpression prevents the regulation by FKBP52 due to its competition for binding to the receptor complex. Importantly, while FKB52 itself is able to interact with cytoskeletal structures [71-73] and links steroid receptor with microtubules, FKBP51 does not show these properties. Perhaps related to these features, it was shown recently that the macrolide FK506 promotes neuroregeneration via FKBP52, the early subcellular relocalization of FKBP52 being required for the efficient outgrowth of neurites [74], whereas FKBP51 antagonizes the effects of FKB52. Thus, binding of these TPR proteins to Hsp90 complexes could show inhibitory or stimulatory action of the client protein, which in turn regulates diverse aspects of the cell physiology [60,75].

2.1.4. Hsp25/27-Human Hsp27 (or mouse homologue Hsp25) belongs to the family of sHsps, which includes nine other isoforms [76]. All these proteins contain a highly conserved region referred to as the $\alpha$-crystallin domain, which contains high percentage of $\beta$-sheets. Hsp25/27 is an ATP-independent chaperone not only implicated in protein folding, but also in shaping the architecture of the cytoskeleton, cell migration, metabolism, cell survival, growth/differentiation, mRNA stabilization, and tumour progression. A variety of stimuli induce phosphorylation, p38 MAP kinase being the most efficient kinase. Phosphorylation of Hsp25/27 favors the dissociation of multimers, which is part of the mechanism providing protection against the negative effects of diverse stress factors. The native size of oligomers is critical, such that the large non-phosphorylated Hsp25/27 oligomers show the greatest protective potential against the adverse effects of tumour necrosis factor- $\alpha$ or reactive oxygen species. Under normal conditions, phosphorylated Hsp25/27 exerts anti-proliferative and antiapoptotic effects and is involved in actin filament dynamics. Anomalous Hsp27 phosphorylation was correlated to pathologies such as viral infections, specific tumour cells, autoimmune diseases, nephropathies, etc. [76].This sHsp modulates the assembly of IFs, participates in the actin polymerization/depolymerization process, and inhibits the aggregation of tubulin [77]. Hsp25/27 prevents actin polymerization when bound, and phosphorylation induces a conformational change resulting in dissociation from the barbed ends of the actin filaments, thus freeing them for the addition of actin monomers [78]. Its overexpression stabilizes microfilaments against deleterious 
effects of hyperthermia and cytochalasin [79]. Accordingly, inhibition of kinase activity that results in Hsp27 phosphorylation or expression of a non-phosphorylable mutant Hsp27 in the fibroblasts inhibits the filament stabilization and inhibits processes dependent on a dynamic microfilament cytoskeleton (e.g., membrane ruffling and pinocytosis) [80].

2.1.5. Chaperonines-Chaperonines are ring-shaped chaperones that encapsulate nonnative proteins in an ATP-dependent manner. In bacteria, the most prominent chaperonin is the GroE machinery, which consists of fourteen GroEL subunits arranged in a cylinder of two heptameric rings, to which the cochaperone GroES, also a heptameric ring, binds [81]. The closely related proteins in mitochondria are called Hsp60 and Hsp10. Non-native protein chains up to $60-\mathrm{kDa}$ are bound in the central cavity of the GroEL cylinder, and the cavity is then closed by the binding of the GroES cofactor in the presence of ATP. As a result, the client protein may fold or it could gain their native structure after release from GroE, depending on the folding properties of the respective protein. Therefore, a GroEbound protein can be refolded isolated from other non-native polypeptide chains, a wise mechanism that prevents massive aggregation. Such a potent protein-folding machine, which is essential in bacteria, should also have enormous importance for the proper management of stressing situations in eukaryotic cells. However, there is no GroE in the eukaryotic or archaeal cells. Nonetheless, the GroE function has been replaced by a distant relative machinery, the $\mathrm{CCT}$ (haperonin-containing the $\underline{\mathrm{T}}$-complex polypeptide-1), also named TRiC (tailless complex polypeptide 1-ring complex), whose architecture and function resembles that of GroE. The CCT/TRiC machinery is the eukaryotic cytoplasmic chaperonin essential for growth of worms and yeasts. Mutations in individual subunits affect assembly of tubulin and actin [82] and have been implicated in neurodegenerative diseases [83, 84]. The main cellular function of CCT/TRiC is to promote the folding of newly synthesized polypeptides, which may be presented by Hsp70 and/or the cochaperone prefoldin [85, 86]. Perhaps due to this reason, CCT/TRiC is not induced by stress, but is instead transcriptionally and functionally linked to protein synthesis [87]. CCT/TRiC forms a large complex composed of eight homologous subunits arranged in two octameric rings stacked back-to-back that form a 1-MDa complex that functions like a cage for protein folding to occur unimpaired by aggregation. Whereas all CCT/TRiC subunits have essentially identical ATPase domains, their polypeptide-binding regions have significantly diverged during evolution to create substrate binding specificity. As a result, a diverse set of polypeptide substrates, estimated to be 5-10\% of newly synthesized cytoplasmic proteins, including actin and tubulin, flux through CCT/TRiC [88]. Actually, due the relative abundance of tubulin and actin, it is thought that a substantial proportion of CCT/TRiC is always occupied by these proteins [89]

\section{Shaping the cytoskeletal architecture}

\subsection{Role of heat-shock proteins}

A small increase in temperature cause rapid and significant protein unfolding along with entanglement of cell architecture and, in a relatively extreme situation, non-specific aggregation of proteins. Therefore, many of the morphological and phenotypic effects of heat stress could be explained as a side effect of the aggregation of proteins with the consequent loss of protein homeostasis. In other words, it is reasonable to assume that the deleterious accumulation of improperly folded proteins is a signal that must trigger homeostatic countermeasures, which indirectly implies that the cell itself could not recognize changes of temperature as such, but via the balance between molecular chaperones and unfolded proteins. There is a plethora of stresses beyond the heat-shock that trigger similar responses, such as metabolic toxics, oxidations, heavy metals, ethanol, irradiation, glucose deprivation, disturbance of calcium homeostasis, etc. One of the major 
damages observed in response to most of these stress conditions are defects of the cytoskeleton.

Mild heat stress leads to the reorganization of actin filaments into stress fibers, while severe heat stress results in the aggregation of vimentin or other filament-forming proteins, leading to the collapse of intermediary, actin, and tubulin networks. Along with the disruption of the cytoskeleton, the loss of the correct localization of organelles and a breakdown of intracellular transport processes are also observed. The cytoskeletal network is not independent for the different types of filaments. When microfilaments are inhibited at the periphery of the cell, an immediate response is the depolymerization of microtubules from the cell edge [90].

Unlike heat-shock proteins, changes in IF levels in response to stress are dependent on both the tissue and gene involved. For example, the astrocytic GFAP expression remain unaltered after heat exposure [91], while vimentin is heat-sensitive since it is elevated in non-neuronal cells and in the microvasculature of the hippocampus [92], but it is diminished in heatexposed rat embryos [93] whose de novo synthesis of Hsp70 and Hsp90 is very rapidly induced (1-8 h after exposure) [94]. Hsp70 is thought to participate in de novo folding pathways of cytoskeletal proteins along with their cognate chaperonines [95]. Notably, the mechanism in eukaryotes involves a physical interaction between Hsp70 and CCT/TRiC near the opening of the chaperonin cavity, indicative of a direct hand-off of substrates [96]. It is unclear whether or not nascent actin and tubulin proteins use the Hsp70 chaperone under certain circumstances.

Heat reduces the extent of microtubule nucleation with significant loss of the centrosomal markers $\gamma$-tubulin and pericentrin, and dynamitin, the 50-kDa subunit of the dyenin/dynactin complex [97]. Nonetheless, heat-shock proteins are recruited to the centrosomes with protective purposes [98], such that in thermotolerant cells, the length of heat shock-induced mitotic delays and the frequency of heat shock-induced division errors are reduced with the close association of Hsp70, but not Hsp27 or Hsp40, with centrosomes. Moreover, the overexpression of Hsp70 restores the localization of dynamitin/p50 at centrosomes and protects cells against most heat-induced mitotic abnormalities [97].

Hsp90 also protects tubulin against thermal denaturation and keeps it in a state compatible with microtubule polymerization [99]. While Hsp90 cannot resolve tubulin aggregates, the chaperone binds early unfolding intermediates preventing their further aggregation.

Protection is maximal at a stoichiometry of two molecules of Hsp90 per molecule of tubulin and does not require ATP, although it is counteracted by specific Hsp90 inhibitors such as geldanamycin. Fig. 2 shows an integrated scheme depicting most of the housekeeping roles of the chaperones that have been discussed in this topic regarding the structural integrity of microtubules and microfilaments (refer to the figure legend for details). Note that due to reasons of simplicity of the scheme, chaperones and IMMs were not included in all the steps, but they are actually characters of each process.

More generally, besides stress conditions, it is known that microtubules reorganize at the interphase-mitosis $\left(\mathrm{G}_{2} / \mathrm{M}\right)$ transition leading to the decrease of the cellular microtubule quantity [100]. Concomitantly, the cytosolic concentration of free tubulin temporarily increases, such that at this point of the cell cycle, Hsp90 can participate in maintaining tubulin dimer integrity and making it available to form the mitotic spindle.

A significant fraction of Hsp90 is also associated to microfilaments along with its cochaperone p23 [101]. When cells are treated with colcemid under conditions that eliminate microtubules, these chaperones condense into bright rope-like bundles located in the immediate perinuclear area and extending toward the cell periphery. Identical images are 
observed with an antibody against vimentin and the pattern seen after colcemid treatment is classical for IFs. Heat-shock causes the spatial arrangement of IFs to change from a fine thread-like network to a large, perinuclear aggregate, whereas in thermotolerant cells, integrity of the IF network is enhanced, and maintenance of this organization is required for establishment of increased heat resistance [102].

When brain tumour cells are treated before heat-shock with angulatin-A, a drug that disrupts vimentin intermediate filaments, they do not acquire thermotolerance, while those treated after receiving a heat-shock gain protection. The vimentin intermediate filaments in cells exposed to the drug prior to heating are arranged in tight perinuclear aggregates unable to return to their normal distribution upon recovery. In contrast, IFs in cells treated with the drug subsequent to thermal stress resume a dispersed organization. Hsc 70 colocalizes with vimentin during these spatial changes, most likely favoring IF stabilization. Importantly, during the very early steps of neuronal differentiation, p23 concentrates in filaments that colocalizes with neurofilaments [103].

\subsection{Hsp90, microtubules and disease}

The association of Hsp90 with microtubules shows several implications. Many proteins responsible for malignant progression within tumour cells are Hsp90-dependent and dozens of oncogenic substrates have been identified to date. Hsp90 regulates pathways that fulfils the six hallmarks of cancer [104], i.e. evasion to apoptosis (Apaf-1, NF- $\kappa B, p 53$, survivin, etc.), sustained angiogenesis (VEGF, VEGFR, Src, HIF-1 $\alpha$, etc.), tissue invasion (MMP2, urokinase, BRMS1, etc.), self-sufficiency in growth signals (Raf-1, Her2, MEK, Bcr-Abl, etc.), insensitivity to anti-growth signals (Weel, CD4, cyclin D, Plk, etc.), limitless replicative potential (telomerase). Therefore, targeting Hsp90 can offer a unified mechanism for chemotherapy. In addition, Hsp90 is overexpressed in malignant cells, and its expression correlates with the proliferation of these cells [105]. Hsp90 inhibitors represent a unique class of compounds that demonstrate high differential selectivity for malignant versus normal cells at concentrations that are well tolerated by humans [31, 106, 107]. There are currently twenty Hsp90-targeted clinical trials in progress and many more inhibitors are in preclinical development, in particular, geldanamycin-derivatives.

Recently, it was shown that Hsp90 inhibits tubulin aggregation and that tubulin polymerization is slower in the presence of Hsp90 than in its absence [99], indicating that the polymerization state of microtubules depends on the cell type and the stress conditions. Hsp90 sequesters soluble (i.e. unstable) tubulin dimers to prevent their irreversible aggregation and to maintain them in a conformational active state for several hours. Once the stress conditions have ended, tubulin is able to form microtubules again, thus, restoring their cellular functions. As it is expected, inhibitors of Hsp90 prevent this action and unstabilize the cell due to microtubule disassembly.

Taxol is a well-known drug for the treatment of cancer that is responsible for the stabilization of microtubules and inhibition of mitosis. Interestingly, taxol induces transcription factors and kinase activation, mimicking the effect of bacterial lipopolysaccharide (LPS), an attribute unrelated to its tubulin-binding properties [108]. Actually, a significant amount of evidence suggests that the LPS-mimetic activity of taxol is independent of $\beta$-tubulin binding. Affinity chromatography experiments with lysates from both mouse brain and macrophage cell lines led to affinity purification of two chaperones, Hsp70 and Hsp90 [109]. In contrast to typical Hsp90-binding drugs, taxol exhibits a stimulatory response, mediating the activation of macrophages and exerting LPS-mimetic effects. The geldanamycin derivative 17-AAG behaves synergistically with taxol-induced apoptosis due to sensitization of tumour cells by suppression of Akt [110], a Ser/Thr protein kinase that is stabilized by Hsp90, as well as its activating kinase PDK1 [111]. Therefore, 
the potential use of Hsp90 inhibitors in combination with proapoptotic therapies represents an exciting new strategy for chemotherapy.

\subsection{Survivin complexes with Hsp90}

The effect on microtubule inhibition is most prominent in mitotic cells where mitotic spindles play a key role in chromosome segregation, and this is why these types of drugs have been classified as anti-mitotic agents. Some chaperone factors such as the Hsp90 client protein surviving are known to localize to the mitotic spindle by interaction with tubulin during mitosis and regulate mitosis [112]. The chaperone survivin is known to be expressed across most tumour cell types and is at the same time absent in normal non-malignant cells, which transforms this molecular chaperone in a potential therapeutic target. Thus, the naturally occurring compound resveratrol (a polyphenol found in grapes and red wine) can be used as a sensitizer for anticancer drug-induced apoptosis by the action of causing cell cycle arrest [113] that produces a dramatic decline in survivin levels in the cells.

Overexpression of survivin has been shown to induce drug resistance against anti-mitotic compounds by stabilizing microtubule network in vincristine/colchicines-resistant oral cancer cells and down-regulation of it restores drug sensitivity [114]. Because Hsp90 binds and stabilizes survivin [115], down-regulation of survivin could be one of the important therapeutic functions of Hsp90 inhibitors such as geldanamycin derivatives. However, a recent report shows evidence that surviving is actually induced by Hsp90-inhibitors [116]. Survivin is a also a dual functional protein since it blocks apoptosis by inhibiting caspases, but it also promotes cancer cell growth by stabilizing microtubules during mitosis. In short, the properties of the Hsp90•survivin complex is far from being clear.

Hsp90 associated with survivin is also overexpressed in cancers [117]. It is thought that the cytoprotection mechanism of this Hsp90•survivin association is centered on the mitochondrial pathway, where surviving has a role in the regulation of mitochondrial apoptosis specifically in tumours [115]. The disruption of the survivin•Hsp90 complex destabilizes surviving leading to mitochondrial apoptosis and ultimately cell growth suppression. However, Hsp90 interaction with survivin also enables stabilization of cofactors such as AKT, Erb-2 and HIF-1 $\alpha$, which can lead to tumour progression [116]. Because survivin is also related to cell division due to its association with the mitotic spindle, there is controversy from the therapeutic point of view regarding how to manage this molecule. Inasmuch as the molecular chaperone Hsp90 binds and stabilizes survivin, it is currently accepted that targeting both proteins at the same time could be beneficial, but a great deal of experimental evidence is certainly required to date to apply in the facts such strategy.

\subsection{Dynamic role of $\mathrm{CCT} / \mathrm{TR}$ iC}

Although $\alpha \beta$-tubulin heterodimers are very stable, the mean half-life of tubulin does not reflect the fact that tubulin is partitioned into multiple states that could have very different turnover rates (i.e. chaperone-monomer complexes, GTP- or GDP-bound dimers, dynamic or stable microtubules, etc.). From the biological perspective, it appears that chaperonin $\mathrm{CCT} / \mathrm{TRiC}$ is a major factor responsible for the stability of microtubules. In the absence of CCT/TRiC function, tubulin cannot fold efficiently and non-native tubulin is removed by proteolysis [118]. The degree of growth arrest strongly correlates with the extent of CCT/ TRiC depletion, indicating that its full activity is required for normal cell growth and division. Depletion of CCT/TRiC does not affect actin polypeptide synthesis, but causes a reduction in levels of native actin and perturbation of actin-based cell motility, and there are no large-scale effects on cytoplasmic protein synthesis or a general heat-shock response during periods of low CCT/TRiC activity. The integrity of the entire cytoskeleton is closely linked to this chaperonin via the folding requirements of actin and tubulin (Fig.2), but the 
role of this chaperonin in cytoskeletal organization remains still unclear. Recent evidence suggests that some CCT/TRiC monomer subunits can influence cytoskeletal organization and polymerization, so the biological activity of the chaperonin may extend beyond the folding of newly synthesized polypeptides, representing other functions for individual subunits distinct from their role in the oligomer [119].

Stress fibers are known to be dynamic structures with regard to actin turnover rates, and it has been suggested that when these rates are decreased, the actin filaments become more prominent [120]. Recent evidence showed that here is a tendency for those fibers with weaker phalloidin staining to be decorated with selected CCT subunits among the number of monomers available for this chaperonin [119], so it is possible that these CCT subunits assist in the addition of new actin monomers onto actin filaments within stress fibers and are therefore found associated with stress fibers that are more dynamic. CCT is also known to interact with other proteins that are genuine chaperonin substrates. Recently, the actin filament remodeling protein gelsolin was identified as a CCT-binding partner [121], and although it does not behave as a classical cochaperone, gelsolin binds to CCT with a high specificity. Gelsolin is involved in the transition of tumours from being non-invasive to invasive [122], which emphasizes the link between cell shape, the actin cytoskeleton, and the functional relevance of chaperonines.

\subsection{CCT/TRiC and disease}

It is clear that the cytoskeletal proteostasis machinery will be engaged in rapidly growing tumour cells and in their response to antitubulin chemotherapeutics. In a novel anti-mitotic approach, a recent study showed that disrupting the CCT/TRiC $\bullet \beta$-tubulin interaction with a small molecule induces apoptosis even in cancer cells resistant to other tubulin-binding chemotherapies [123]. CCT/TRiC has another link to cancer whereby its interaction with the von Hippel-Lindau (VHL) tumour suppressor protein is essential for assembly of the VHL E3-ubiquitin ligase complex; tumour-inducing mutations in VHL specifically disrupt CCT/ TRiC binding [124]. Bisphosphonates, which are used to treat cancer-induced bone loss (and which are the subject of clinical trials against breast cancer due to their effects on the migration, invasion and proliferation of cancer cells) trigger a strong up-regulation of TBCB and prominent disruption of the microtubule cytoskeleton [125]. Drugs targeting tubulin folding cofactors could be beneficial because they would be tubulin-specific and could have anti-proliferative and anti-metastatic effects [126]. Tubulin is degraded in response to microtubule-destabilizing drugs, so a parallel increase in the concentration of soluble tubulin is observed. When the function of CCT/TRiC is impaired, tubulin does not fold efficiently and the non-native tubulin is rapidly removed by proteolysis. Accordingly, treatments of cells with the proteasome inhibitor MG132 demonstrated that $\alpha$-tubulin and $\beta$-tubulin are highly ubiquitylated [127]. Moreover, tubulin from various human cell types is targeted by cancer-preventive isothiocyanates which covalently modify tubulins and induce conformational changes that trigger proteasome-dependent tubulin degradation [128]. Interestingly, the overexpression of $\beta$-tubulin is toxic in Sacharomyces cerevisiae, but $\alpha$ tubulin overexpression is well tolerated [129]. However, this particular effect is not observed in mammalian cells, perhaps due to the autoregulation mechanisms for $\beta$-tubulin degradation.

PolyQ-expanded huntingtin has also been identified as a TRiC substrate [130]. TRiC partially colocalizes with huntingtin aggregates and remodeled their morphology while reducing cell death. PolyQ-expanded huntingtin and other amyloidogenic proteins tend to form fibrillar aggregates possessing a cross- $\beta$ core with extensive $\beta$-sheet structure. Inasmuch as TRiC substrates tend to be large and are hydrophobic proteins with $\beta$-strand regions of high propensity to aggregate [131], it is therefore plausible that TRiC can regulate the conformation of huntingtin (and also other amyloidogenic proteins) by direct binding to 
such $\beta$-sheet structures formed immediately after the initiation of the aggregation process, perhaps directly after its synthesis or the proteolytic generation of aggregation prone fragments.

\subsection{Tau protein as a chaperone-assisted factor}

Tau is one of several types of microtubule-associated proteins that regulate the assembly and stability of microtubule networks. It is very abundant in neurons, mostly localized in axons, and has six isoforms produced from a single gene through alternative RNA splicing that are identified by the number of binding domains [132]. Tau has received great attention because mounting evidence indicates that hyperphosphorylation of Tau is the origin of Alzheimer's disease [133]. Tau proteins interact with tubulins to promote their assembly into microtubules, which in turn are stabilized by two manners, due to isoform-specific binding to the filament and by serine/threonine kinase phosphorylations. It is thought to be an inherently unfolded protein that undergoes aggregation by hyperphosphorylation, followed by folding and protein cleavage $[134,135]$. These posttranslational modifications can impact the interaction of Tau with microtubules and thus, there may be specific isoforms of Tau that are preferred chaperone substrates relative to others. Importantly, Tau is a client protein of Hsp90 complexes. FKBP51 and FKBP52 are also co-chaperones of Hsp90•Tau complexes $[136,137]$, as well as the IMM-like Ser/Thr phosphatase PP5. Fig. 3A shows a comparative scheme of the common and highly homologous domains of these three IMMs close-related to the Tau•microtubule architecture.

The peptidylprolyl-cis/trans-isomerase activity of those IMMs catalyzes phosphorylationdependent rotation in pSer/Thr-Pro peptide bond. The proline switch in the Tau conformation triggers the PP5-dependent dephosphorylation of Ser/Thr residues phosphorylated by two well-known Tau kinases, Cdk5 and GSK-3b [138-140] (Fig. 3B). Subsequently, the PP5 dephosphorylated Tau protein can be shuttled back to the microtubules. It seems that high-affinity binding of abnormal Tau to Hsp90 complexes may have some counteracting effect on the aggregation process, since Hsp90 inhibitors can ameliorate the aggregation process in several neurodegenerative diseases [141]. Initially, Hsp40, Hsp70 and Hsp90 form a complex with mutated or distinctively phosphorylated Tau species and subsequently recruit PP5 to facilitate dephosphorylation and refolding process. When this is undermined, the complex engages the CHIP-dependent pathway, which polyubiquitinates the Tau protein and triggers proteasomal degradation (Fig.3B).

It has recently been reported that other chaperone proteins, including Hsp27, Hsp70 and CHIP (carboxy-terminus of $\underline{H} s c 70$-interacting protein), can recognize abnormal Tau and reduce its concentration by facilitating its dephosphorylation and degradation. Hsp27 preferentially binds to hyperphosphorylated Tau as well as paired helical filamentous Tau, but not to non-phosphorylated Tau [142]. The expression of another sHsp, alphaB-crystallin has been found in glial inclusions of tauopathies [143]. While Hsp27 also increases Tau phosphorylation at $\operatorname{Ser}^{262}$, alphaB-crystallin decreases phosphorylated Tau and GSK-3 $\beta$ levels [144]. Interestingly, Hsp27 is cross-linked with Tau in neurofilaments from Alzheimer's disease brains, and positive correlations have been found in the soluble protein levels from of these brain tissues between Tau and molecular Hsp27, Hsp40, Hsp90, alphaB-crystallin and CHIP [145]. Conversely, the levels of heat-shock proteins were inversely correlated with the levels of granulated Tau oligomers, an intermediate of Tau filaments. In a separate study, increased levels of Hsp70 and Hsp90 were found to promote Tau solubility and microtubule binding in various cellular models [146]. Subsequent studies show that Tau binds directly to Hsp70, and Bag1 has a role in this interaction [147]. Taken together, these findings suggest that chaperones are necessary to maintain Tau in a nonaggregated state, a consequence that may ultimately be deleterious for the brain. A novel mechanism demonstrating that there are two pathways that can lead to opposing outcomes 
for Tau biology with regard to Hsp90; some chaperones preserve Tau whereas others promote its degradation [148]. Furthermore, mutant Tau and not wild-type Tau, is maintained by Hsp90 in tauopathies, and the inhibition of Hsp90 leads to reductions in the pathogenicity of these mutant species [141].

\section{Role of immunophilins in the organization of cytoskeleton}

\subsection{FKBP51 and FKBP52}

FKBP52 was first described associated to microtubules in $1995[73,149]$ by confocal microscopy studies and biochemical methods. The IMM was present in the subcellular fractions containing either soluble proteins released from cells exposed to NP40 detergent, or proteins released from the cytoskeleton exposed to calcium ions (i.e. in microtubuledepolymerizing conditions). Exposure of cells to FK506 and rapamycin did not modify significantly the colocalization with microtubules, indicating that the PPIase activity is not required for such interaction. During mitosis, FKBP52 segregates from the region of the chromosomes being mainly localized with the mitotic apparatus (centrosome, spindle and interzone separating the chromosomes) [73]. Then, it was shown that this IMM associates to dynein motors $[59,150]$, and more recently, it was postulated that FKBP52 can prevent tubulin polymerization [71].

A high percentage of prolines are common to most intrinsically disordered proteins, and Tau is no exception [151]. Nearly $10 \%$ of full-length Tau is composed of proline residues and more than $20 \%$ of the residues between $\mathrm{I}^{151}$ and $\mathrm{Q}^{244}$ are proline. Most of the known functions of Tau are mediated through microtubule binding domains distal to this prolinerich region. As mentioned above, recent studies have revealed that both IMMs, FKBP51 and FKBP52, interact directly with Tau protein $[136,137]$. It has also been shown that Tau phosphorylation increases its binding affinity for FKBP52, whereas the overexpression of the IMM could prevent the accumulation of Tau protein induced by nerve growth factor. While FKBP52 appears to inhibit tubulin polymerization, which is triggered by Tau protein in vitro [136], FKBP51 stabilizes microtubules in a PPIase activity-dependent manner and also enhances the association of Tau with Hsp90, although the FKBP51/Tau interaction is not entirely dependent on the chaperone [137]. In this complex, phosphorylated Tau is in a trans configuration, and the PPIase activity of FKBP51 isomerizes Tau to a cis configuration, which enhances dephosphorylation of Tau by the IMM-like phosphatase PP5. This is a critical event because dephosphorylated Tau is recycled to microtubules and stabilizes them. On the other hand, highly phosphorylated Tau exhibits reduced microtubule binding, leading to a loss of microtubule integrity.

Because both FKBP51 and FKBP52 possess PPIase activity and are capable to bind phosphorylated Tau (Fig.3), it is currently unclear why FKBP51 is selectively able to isomerize Tau and promote microtubule polymerization. One possible explanation could be the fact that both TPR-domain IMMs, as well as CyP40 and PP5, compete for a common Hsp90 binding-site in steroid receptor complexes $[60,150]$, so it would be possible that a similar competition may take place in the phospho-Tau $\bullet$ Hsp90 heterocomplex containing a TPR-domain cochaperone. In turn, the qualitative composition of such heterocomplex may depend on the relative abundance of TPR proteins in a given cell, just like it has been postulated for steroid receptors [60, 152, 153]. Moreover, structural comparison of FKBP51 and FKBP52 revealed that the TPR domains have different spatial orientations [70].

\subsection{Roles of FKBPs on the cytoskeleton structure during the early neuronal differentiation}

The fact that FKBP51 and FKBP52 affects neurite length may explain, at least in part, the observations that the IMM ligand FK506 exhibits potent neurotrophic effects [74]. FK506 has been shown to promote neuroprotective and neuroregenerative effects in a number of 
injury models. The persistence of the capability to hasten nerve outgrowth by FK506derivatives devoid of immunosuppressive effects indicated that both effects are independent [154], and experiments with mice where the FKBPIA gene was knocked-out clearly showed that such neurotrophic effect is not mediated by FK506•FKBP12 complexes [155]. Recently, it was demonstrated that the FKBP52•Hsp90•p23 complex forms a perinuclear structure in undifferentiated $\mathrm{N} 2 \mathrm{a}$ neuroblastoma cells and hippocampal cells isolated from rat embryos [74]. This peculiar perinuclear structure undergoes a rapid subcellular redistribution along the cytoplasm (Fig.4A), which is detectable within the first hour of stimulation with FK506. Importantly, FKBP52 is concentrated in terminal axons and arborization areas. In agreement with the potential relevance of this IMM, knock-down experiments showed that FKBP52 plays a key role in the architecture of these nuclear rings since these structures faded in most cells (if not all of them) where the expression of the IMM was abrogated. Importantly, both the rate of cell differentiation and neurite outgrowth were also inhibited. Therefore, there is a direct relationship between the disassembly of the chaperone complex and the progression of neuronal differentiation. The chaperones migrate to the cytoplasm and become associated with cytoskeletal structures, whereas the nuclear areas originally occupied by them in undifferentiated cells become transcriptionally active after chaperones redistribute.

In contrast to FKBP52, FKBP51 is not induced during differentiation, remains in the cell body and replaces FKBP52 in the annular structures of the nucleus complexed with Hsp70 [74]. While the overexpression of FKBP52 induces fast differentiation of N2a neuroblastoma cells and neurites are longer, the expected opposite action is observed after knocking-down FKBP52. On the other hand, FKBP51 overexpression decreases both the neurite length and the rate of cell differentiation, whereas its knock-down favors neurite outgrowth. In other words, it appears that both IMMs have antagonistic action during the very early steps of neuronal differentiation.

Surprisingly, microtubules of undifferentiated neurons show a diffuse cytoplasmic distribution, whereas they are arranged in the expected filamentary pattern after stimulation with FK506 (Fig.4B). Simultaneously, the Hsp90 cochaperone p23 becomes associated to neurofilaments (Fig.4C) and seems to be dissociated from both Hsp90 and FKBP52. Importantly, after 5-6 days in culture with FK506 and no other trophic factor added to the medium, embryonic day 17 rat hippocampal neurons show a new redistribution of FKBP52 only, such that the IMM is concentrated back in nuclei but, in contrast to what it was observed in the undifferentiated state, FKBP52 distributes in the nucleus a diffuse manner and shows no particular arrangement. All these observations suggest an active role of the $\mathrm{IMM} \bullet \mathrm{Hsp} 90 \bullet \mathrm{p} 23$ complex in the arrangement of the neuronal cytoskeleton during the early steps of cell differentiation. The above-described observations by Quinta et al. [103] apparently collide with those reported by Chambroud $[71,136]$ in that these studies reported that overexpression of FKBP52 reduced neurite outgrowth in response to 5 days in culture with nerve growth factor in PC12 pheochromocytoma cells always maintained in a medium with fetal serum. Therefore, there are important experimental differences between both studies with respect to the cell type, length of stimulation in culture, and culture conditions that justify those differences.

S100A proteins constitute a large family of calcium binding proteins which are linked to many neurological disorders, inflammatory diseases, innate immunity, wound healing, and cancer processes [156]. Several S100A proteins can bind to the TPR domain of FKBP52 protein, which leads to the dissociation of the Hsp90•FKBP52 complex in the presence of calcium [157]. Apart from the possible crosstalk between S100A proteins and pro- or antiangiogenic factors, S100A4 and A13 have been reported to participate directly in the angiogenic process in other tissues. Because the common denominator able to affect the 
biological activity of S100A proteins in all these biological processes is calcium homeostasis, it could be implied that the function of FKBP52 can be regulated by calcium within the cell, just like Tau phosphorylation and pathology in Alzheimer disease are regulated. Moreover, FKBP52 counts with a calmodulin binding domain, whose biological function is still enigmatic. Recently, FKBP52-dependent regulation of TRPC calcium channels was reported in neurons [158].

\subsection{The immunophilin-like protein-phosphatase PP5}

The IMM-like protein phosphatase 5, PP5, has three TPR units for binding to the Hsp90 chaperone, a PPIase-like domain, and the Ser/Thr phosphatase sequence [159] (Fig. 3A). PP5 can bind to trafficking glucocorticoid receptor heterocomplexes, is associated to microtubules and interacts with dynein motors [66, 160-162]. The binding to Hsp90 complex activates the PP5 enzyme which is inactive outside the complex. As it was discussed before, PP5 dephosphorylates Tau protein, and this dephosphorylation is connected to the aggregates formed in Alzheimer disease [163]. The role of this microtubule-associated IMM in the protection against Tau pathology is largely unknown, although it is inferred that PP5, which is highly expressed in mammalian brain, possesses a great potential to dephosphorylate Tau protein e.g. in Hsp90-FKBP51 complexes and enhance the binding of Tau to microtubules.

\section{Post-translational modifications}

In addition to chaperone-assisted folding and assembly, covalent modification is often an integral part of the biogenesis pathway leading to functional proteins. These posttranslational modifications affect folding or they can act as reversible switches able to regulate the features of cytoskeletal proteins. In the case of actin, there is little or no evidence in this regard, whereas tubulin is subject to a number of reversible modifications that includes detyrosination, glutamylation/glycylation and acetylation [164]. Detyrosination involves the removal of the gene-encoded C-terminal tyrosine of $\alpha$-tubulin in microtubule polymers by a still unidentified carboxypeptidase, this detyrosination being important for kinesin-1 preferential binding to microtubules [165] and the consequent transport of vimentin filaments [166]. On the other hand, glutamylation/glycylation involve the addition of glutamate or glycine residues onto glutamate residues in the C-terminal tails of both $\alpha$ and $\beta$-tubulin [167]. While glycylation is mainly limited to tubulin incorporated into axonemes (cilia and flagella), glutamylation is more prevalent in neuronal cells, centrioles, and the mitotic spindle. Both modifications have been found on the same tubulin C-terminal end and it has been proposed that there are cross-talks between the $\alpha$ - and $\beta$-tubulin tails that regulate the type and extent for each post-translational modification [168].

It is accepted that most tubulin modifications occur on polymerized microtubules, whereas the substrate for the reversal of these modifications is the free tubulin heterodimer [169]. Nonetheless, this heuristic model still deserves more conclusive experimental support. Some of the tubulin-modifying enzymes might compete or cooperate with other factors involved in regulating microtubule function. Thus, the class II histone-deacetylase HDAC6, known to function as a potent $\alpha$-tubulin deacetylase, binds to several microtubule-binding proteins such as plus-end marker proteins [170]. Recent evidence suggests that tubulin acetylation is involved in neurodegenerative diseases [171]. The list of HDAC6 partners with which the enzyme can interact has expanded considerably during last several years. Unquestionably, the regulation of HDAC6 activity by Hsp90 is one of the most striking [172, 173], the chaperone itself being substrate of the enzyme. When HDAC6 was knocked-down, Hsp90 was hyperacetylated and much less of the Hsp90 cochaperone p23 was recovered associated to Hsp90. The glucocorticoid receptor becomes defective in ligand binding, nuclear translocation, and gene activation. The acetylated Hsp90 has a lower affinity for ATP than 
the wild-type Hsp90, and the dynamic the glucocorticoid receptor•Hsp90 heterocomplex assembly/disassembly that occurs in HDAC6 knockdown cells is manifest as a $~ 100$-fold shift to the right versus wild-type cells in the dose response of steroid for transcriptional activation. However, the receptor itself is not affected by HDAC6 [173].

Several other targets besides tubulin and Hsp90 were shown to be deacetylated by HDAC6. Among them, cortactin, an actin-binding protein promoting Arp2/3-dependent actin nucleation [174], whereas Hsp90 can regulate actin polymerization by interacting with and enhancing the function of the Neural Wiskott-Aldrich syndrome protein, N-WASP [175]. Involvement of Hsp90 in HDAC6-dependent actin remodeling was also recently reported [176]. Because assembly of tubulin is affected by Hsp90, both targets of HDAC6, cortactin and Hsp90, could mediate the effect of HDAC6 inhibition on microtubules acting, directly or indirectly, via remodeling of the actin cytoskeleton. The putative participation of Hsp90 or cortactin in the effect of HDAC6 inhibition on microtubule dynamics requires the physical presence of HDAC6, rather than just increased acetylation of Hsp90 or cortactin, since HDAC6 knockdown, which enhances such acetylation, is not sufficient for alteration of microtubule dynamics.

\section{Envoy}

Clearly, molecular chaperones and immunophilins perform different but cooperating roles in the regulation of cytoskeleton function. To date, many questions concerning the interplay of these proteins and the cytoskeleton still remains to be fully elucidated. Clarification of these issues requires a better understanding of our knowledge for all groups of proteins, molecular chaperones, immunophilins, and cytoskeletal elements. Nevertheless, this is not an easy issue. Within cells, the protein synthesis and their subsequent folding take place at the ribosome surface. Both processes are rapid and occur in a protein-rich milieu that exerts different influences on the final product. As a case in point, it is not always possible to differentiate in vivo the individual effects of molecular chaperones that act cooperatively and/or sequentially on nascent proteins, so the problem was partially overcome by analysis of cells with mutated chaperones. Even though this approach has provided many answers, it is only limited to those organisms for which genetic manipulation is possible. On the other hand, while studies in vitro allow defined conditions, they suffer from the obvious limitations imposed by the artificial environment. Protein concentration and diversity in vitro are often much lower than in the cytoplasm and only one of many cooperative reactions influencing protein folding may be under study. Thus, a molecular chaperone might seem unrelated to a particular cytoskeletal component only because, for example, a cochaperone is missing or not properly activated. Conversely, molecular chaperones tend to recognize hydrophobic regions exposed to the aqueous environment, a generalized mechanism providing ample opportunity for non-specific interactions. This concern is especially pertinent in an in vitro situation, where relatively high levels of a limited number of proteins dissolved in low salt non-physiological buffers may drive inappropriate reactions. Artifactual protein-protein associations are also encountered when searching cells for microtubule-associated proteins, an example which provides a strong cautionary message to the study of chaperone-substrate interactions. In spite of all these problems associated with their study, the available evidence proves univocally that all types of molecular chaperones not only assist the formation of cytoskeletal proteins, but also influence the structural and functional organization of microtubules, microfilaments and intermediate filaments. This has considerable consequences in the progression of the cell cycle, cell death, cellular adaptive response to stress, cell differentiation, neuroprotection, neuroregeneration, progression and aggressiveness of different tumor phenotypes, etc. Therefore, research into virtual drug design and protein configuration determination is 
gaining progressive attention since drug development in both fields, biology and medicine, recognizes now the potential for multipoint interventions.

Highlights

Cytoskeletal structure is continually remodeled to accommodate normal cell growth and to respond to pathophysiological cues. As a consequence, several cytoskeletoninteracting proteins become involved in a variety of cellular processes such as cell growth and division, cell movement, vesicle transportation, cellular organelle location and function, localization and distribution of membrane receptors, and cell-cell communication. Molecular chaperones and immunophilins are counted among the most important proteins that interact closely with the cytoskeleton network, in particular with microtubules and microtubule-associated factors. In several situations, heat-shock proteins and immunophilins work together as a functionally active heterocomplex, although both types of proteins also show independent actions. In circumstances where homeostasis is affected by environmental stresses or due to genetic alterations, chaperone proteins help to stabilize the system. Molecular chaperones facilitate the assembly, disassembly and/or folding/refolding of cytoskeletal proteins, so they prevent aberrant protein aggregation. Nonetheless, the roles of heat-shock proteins and immunophilins are not limited to solve abnormal situations, but they also have an active participation during the normal differentiation process of the cell and are key factors for many structural and functional rearrangements during this course of action. Cytoskeleton modifications leading to altered localization of nuclear factors may result in loss- or gain-of-function of such factors, which affects the cell cycle and cell development. Therefore, cytoskeletal components are attractive therapeutic targets, particularly microtubules, to prevent pathological situations such as rapidly dividing tumour cells or to favor the process of cell differentiation in other cases. In this review we will address some classical and novel aspects of key regulatory functions of heat-shock proteins and immunophilins as housekeeping factors of the cytoskeletal network.

\section{Abbreviations}

$\begin{array}{ll}\text { IMM } & \text { Immunophilin } \\ \text { FKBP } & \text { FK506-binding protein } \\ \text { TPR } & \text { Tetratricopeptide repeat } \\ \text { PPIase } & \text { peptidylprolyl-(cis/trans)-isomerase activity } \\ \text { Hsp } & \text { heat-shock protein } \\ \text { sHsp } & \text { small Hsp, Hsc, constitutively expressed heat-shock cognate 70-kDa } \\ \text { CHIP } & \text { carboxy-terminus of Hsc70-interacting protein } \\ \text { IF } & \text { intermediate filament } \\ \text { GFAP } & \text { glial fibrillary acidic protein } \\ \text { CCT } & \text { chaperonin-containing the T-complex polypeptide-1 } \\ \text { TRiC } & \text { tailless complex polypeptide 1-ring complex; histone deacetylase;histone } \\ & \text { deacetylase }\end{array}$




\section{Acknowledgments}

The experimental work described in this review was supported by grants from Universidad de Buenos Aires (UBACyT Program). ANPCyT PICT 2010-1170 and the Guggenheim Foundation (to M.D.G.), and ANPCyT PICT 2007-0640 and NIH-FIRCA award R03TW008143-01A1 (to G.P.P.).

\section{References}

1. Erickson HP. Bioessays. 2007; 29(7):668-677. [PubMed: 17563102]

2. Shih YL, Rothfield L. Microbiol Mol Biol Rev. 2006; 70(3):729-754. [PubMed: 16959967]

3. Wade RH. Mol Biotechnol. 2009; 43(2):177-191. [PubMed: 19565362]

4. Vogel J, Drapkin B, Oomen J, Beach D, Bloom K, Snyder M. Dev Cell. 2001; 1(5):621-631. [PubMed: 11709183]

5. Mogilner A, Oster G. Curr Biol. 2003; 13(18):R721-R733. [PubMed: 13678614]

6. Defeu Soufo HJ, Graumann PL. EMBO Rep. 2004; 5(8):789-794. [PubMed: 15272301]

7. Wiesner S, Helfer E, Didry D, Ducouret G, Lafuma F, Carlier MF, Pantaloni D. J Cell Biol. 2003; 160(3):387-398. [PubMed: 12551957]

8. Khatau SB, Kim DH, Hale CM, Bloom RJ, Wirtz D. Nucleus. 2010; 1(4):337-342. [PubMed: 21327082]

9. Wirtz D, Khatau SB. Nat Mater. 2010; 9(10):788-790. [PubMed: 20864937]

10. Toivola DM, Tao GZ, Habtezion A, Liao J, Omary MB. Trends Cell Biol. 2005; 15(11):608-617. [PubMed: 16202602]

11. Capetanaki Y, Bloch RJ, Kouloumenta A, Mavroidis M, Psarras S. Exp Cell Res. 2007; 313(10): 2063-2076. [PubMed: 17509566]

12. Szeverenyi I, Cassidy AJ, Chung CW, Lee BT, Common JE, Ogg SC, Chen H, Sim SY, Goh WL, Ng KW, Simpson JA, Chee LL, Eng GH, Li B, Lunny DP, Chuon D, Venkatesh A, Khoo KH, McLean WH, Lim YP, Lane EB. Hum Mutat. 2008; 29(3):351-360. [PubMed: 18033728]

13. Ehler E, Perriard JC. Heart Fail Rev. 2000; 5(3):259-269. [PubMed: 16228909]

14. Dutsch-Wicherek M. Am J Reprod Immunol. 2010; 63:181-188. [PubMed: 20085563]

15. Sarria AJ, Panini SR, Evans RM. J Biol Chem. 1992; 267:19455-19463. [PubMed: 1527066]

16. Gilyarov AV. Neurosci Behav Physiol. 2008; 38:165-169. [PubMed: 18197384]

17. Herrmann H, Strelkov SV, Burkhard P, Aebi U. J Clin Invest. 2009; 119(7):1772-1783. [PubMed: 19587452]

18. Omary MB. J Clin Invest. 2009; 119(7):1756-1762. [PubMed: 19587450]

19. Toivola DM, Strnad P, Habtezion A, Omary MB. Trends Cell Biol. 2010; 20(2):79-91. [PubMed: 20045331]

20. Green KJ, Bohringer M, Gocken T, Jones JC. Adv Protein Chem. 2005; 70:143-202. [PubMed: 15837516]

21. Pallari HM, Eriksson JE. Sci STKE. 2006; 2006(366) pe53.

22. Cabeen MT, Jacobs-Wagner C. Annu Rev Genet. 2010; 44:365-392. [PubMed: 21047262]

23. Aylett CH, Wang Q, Michie KA, Amos LA, Lowe J. Proc Natl Acad Sci U S A. 2010; 107(46): 19766-19771. [PubMed: 20974911]

24. Michie KA, Lowe J. Annu Rev Biochem. 2006; 75:467-492. [PubMed: 16756499]

25. Bork P, Sander C, Valencia A. Proc Natl Acad Sci U S A. 1992; 89(16):7290-7294. [PubMed: 1323828]

26. Aravind L, Koonin EV. J Mol Biol. 1999; 287(5):1023-1040. [PubMed: 10222208]

27. Ellis RJ. Cell Stress Chaperones. 1996; 111:155-160. [PubMed: 9222600]

28. Jakob U, Muse W, Eser M, Bardwell JC. Cell. 1999; 96(3):341-352. [PubMed: 10025400]

29. Mayer MP. Mol Cell. 2010; 39(3):321-331. [PubMed: 20705236]

30. Richter K, Haslbeck M, Buchner J. Mol Cell. 2010; 40(2):253-266. [PubMed: 20965420]

31. Trepel J, Mollapour M, Giaccone G, Neckers L. Nat Rev Cancer. 2010; 10(8):537-549. [PubMed: 20651736] 
32. Echeverria PC, Picard D. Biochim Biophys Acta. 2010; 1803(6):641-649. [PubMed: 20006655]

33. Galigniana MD, Echeverría PC, Erlejman AG, Piwien-Pilipuk G. Nucleus. 2010; 1:299-308. [PubMed: 21113270]

34. Pratt WB, Galigniana MD, Morishima Y, Murphy PJ. Essays Biochem. 2004; 40:41-58. [PubMed: 15242338]

35. Sreedhar AS, Kalmar E, Csermely P, Shen YF. FEBS Lett. 2004; 562(1-3):11-15. [PubMed: 15069952]

36. Pratt WB, Toft DO. Endocr Rev. 1997; 18(3):306-360. [PubMed: 9183567]

37. Luo W, Sun W, Taldone T, Rodina A, Chiosis G. Mol Neurodegener. 2010; 5:24. [PubMed: 20525284]

38. DeZwaan DC, Freeman BC. Trends Biochem Sci. 2010; 35(7):384-391. [PubMed: 20236825]

39. Kadota Y, Shirasu K, Guerois R. Trends Biochem Sci. 2010; 35(4):199-207. [PubMed: 20096590]

40. Galigniana MD. Biochem J. 1993; 333(Pt 3):555-563. [PubMed: 9677313]

41. Vicent GP, Pecci A, Ghini A, Piwien-Pilipuk G, Galigniana MD. Exp Cell Res. 2002; 276(2):142154. [PubMed: 12027445]

42. Harrell JM, Murphy PJ, Morishima Y, Chen H, Mansfield JF, Galigniana MD, Pratt WB. J Biol Chem. 2004; 279(52):54647-54654. [PubMed: 15485845]

43. Chadli A, Bouhouche I, Sullivan W, Stensgard B, McMahon N, Catelli MG, Toft DO. Proc Natl Acad Sci U S A. 2000; 97(23):12524-12529. [PubMed: 11050175]

44. Pratt WB, Toft DO. Exp Biol Med (Maywood). 2003; 228(2):111-133. [PubMed: 12563018]

45. Kanelakis KC, Murphy PJ, Galigniana MD, Morishima Y, Takayama S, Reed JC, Toft DO, Pratt WB. Biochemistry. 2000; 39(46):14314-14321. [PubMed: 11087380]

46. Karagoz GE, Duarte AM, Ippel H, Uetrecht C, Sinnige T, van Rosmalen M, Hausmann J, Heck AJ, Boelens R, Rudiger SG. Proc Natl Acad Sci U S A. 2011; 108(2):580-585. [PubMed: 21183720]

47. Tanioka T, Nakatani Y, Semmyo N, Murakami M, Kudo I. J Biol Chem. 2000; 275(42):3277532782. [PubMed: 10922363]

48. Grad I, McKee TA, Ludwig SM, Hoyle GW, Ruiz P, Wurst W, Floss T, Miller CA 3rd, Picard D. Mol Cell Biol. 2006; 26(23):8976-8983. [PubMed: 17000766]

49. Goldfarb SB, Kashlan OB, Watkins JN, Suaud L, Yan W, Kleyman TR, Rubenstein RC. Proc Natl Acad Sci U S A. 2006; 103(15):5817-5822. [PubMed: 16585520]

50. Kampinga HH, Craig EA. Nat Rev Mol Cell Biol. 2010; 11(8):579-592. [PubMed: 20651708]

51. Bercovich B, Stancovski I, Mayer A, Blumenfeld N, Laszlo A, Schwartz AL, Ciechanover A. J Biol Chem. 1997; 272(14):9002-9010. [PubMed: 9083024]

52. Klucken J, Shin Y, Masliah E, Hyman BT, McLean PJ. J Biol Chem. 2004; 279(24):25497-25502. [PubMed: 15044495]

53. Jana NR, Tanaka M, Wang G, Nukina N. Hum Mol Genet. 2000; 9(13):2009-2018. [PubMed: 10942430]

54. Bailey CK, Andriola IF, Kampinga HH, Merry DE. Hum Mol Genet. 2002; 11(5):515-523. [PubMed: 11875046]

55. Chan HY, Warrick JM, Gray-Board GL, Paulson HL, Bonini NM. Hum Mol Genet. 2000; 9(19): 2811-2820. [PubMed: 11092757]

56. Adachi H, Katsuno M, Minamiyama M, Sang C, Pagoulatos G, Angelidis C, Kusakabe M, Yoshiki A, Kobayashi Y, Doyu M, Sobue G. J Neurosci. 2003; 23(6):2203-2211. [PubMed: 12657679]

57. Kang CB, Hong Y, Dhe-Paganon S, Yoon HS. Neurosignals. 2008; 16(4):318-325. [PubMed: 18635947]

58. Davies TH, Sanchez ER. Int J Biochem Cell Biol. 2005; 37(1):42-47. [PubMed: 15381148]

59. Galigniana MD, Radanyi C, Renoir JM, Housley PR, Pratt WB. J Biol Chem. 2001; 276(18): 14884-14889. [PubMed: 11278753]

60. Galigniana MD, Erlejman AG, Monte M, Gomez-Sanchez C, Piwien-Pilipuk G. Mol Cell Biol. 2010; 30(5):1285-1298. [PubMed: 20038533]

61. Thomas M, Harrell JM, Morishima Y, Peng HM, Pratt WB, Lieberman AP. Hum Mol Genet. 2006; 15(11):1876-1883. [PubMed: 16644868] 
62. Galigniana MD, Harrell JM, O'Hagen HM, Ljungman M, Pratt WB. J Biol Chem. 2004; 279(21): 22483-22489. [PubMed: 15004035]

63. Colo GP, Rubio MF, Nojek IM, Werbajh SE, Echeverria PC, Alvarado CV, Nahmod VE, Galigniana MD, Costas MA. Oncogene. 2008; 27(17):2430-2444. [PubMed: 17968310]

64. Zhao W, Zhong L, Wu J, Chen L, Qing K, Weigel-Kelley KA, Larsen SH, Shou W, Warrington KH Jr. Srivastava A. Virology. 2006; 353(2):283-293. [PubMed: 16828834]

65. Galigniana MD, Morishima Y, Gallay PA, Pratt WB. J Biol Chem. 2004; 279(53):55754-55759. [PubMed: 15496417]

66. Galigniana MD, Harrell JM, Murphy PJ, Chinkers M, Radanyi C, Renoir JM, Zhang M, Pratt WB. Biochemistry. 2002; 41(46):13602-13610. [PubMed: 12427021]

67. Rycyzyn MA, Reilly SC, O'Malley K, Clevenger CV. Mol Endocrinol. 2000; 14(8):1175-1186. [PubMed: 10935542]

68. Cox MB, Riggs DL, Hessling M, Schumacher F, Buchner J, Smith DF. Mol Endocrinol. 2007; 21(12):2956-2967. [PubMed: 17717070]

69. Sinars CR, Cheung-Flynn J, Rimerman RA, Scammell JG, Smith DF, Clardy J. Proc Natl Acad Sci U S A. 2003; 100(3):868-873. [PubMed: 12538866]

70. Wu B, Li P, Liu Y, Lou Z, Ding Y, Shu C, Ye S, Bartlam M, Shen B, Rao Z. Proc Natl Acad Sci U S A. 2004; 101(22):8348-8353. [PubMed: 15159550]

71. Chambraud B, Belabes H, Fontaine-Lenoir V, Fellous A, Baulieu EE. Faseb J. 2007; 21(11):2787_ 2797. [PubMed: 17435176]

72. Czar MJ, Owens-Grillo JK, Yem AW, Leach KL, Deibel MR Jr. Welsh MJ, Pratt WB. Mol Endocrinol. 1994; 8(12):1731-1741. [PubMed: 7708060]

73. Perrot-Applanat M, Cibert C, Geraud G, Renoir JM, Baulieu EE. J Cell Sci. 1995; 108(Pt 5):20372051. [PubMed: 7544801]

74. Quintá HR, Maschi D, Gomez-Sanchez C, Piwien Pilipuk G, Galigniana MD. J Neurochem. 2010; 115:716-734. [PubMed: 20796173]

75. Gallo LI, Ghini AA, Pilipuk GP, Galigniana MD. Biochemistry. 2007; 46(49):14044-14057. [PubMed: 18001136]

76. Kostenko S, Moens U. Cell Mol Life Sci. 2009; 66:3289-3307. [PubMed: 19593530]

77. Beck FX, Neuhofer W, Müller E. Am J Physiol Renal Physiol. 2000; 279:F203-F215. [PubMed: 10919839]

78. Benndorf R, Hayess K, Ryazantsev S, Wieske M, Behlke J, Lutsch G. J Biol Chem. 1994; 269:20780-20784. [PubMed: 8051180]

79. Lavoie JN, Gingras-Breton G, Tanguay RM, Landry J. J Biol Chem. 1993; 268:3420-3429. [PubMed: 8429018]

80. Lavoie JN, Hickey E, Weber LA, Landry J. J Biol Chem. 1993:24210-24214. [PubMed: 8226968] 81. Horwich AL, Farr GW, Fenton WA. Chem Rev. 2006; 106(5):1917-1930. [PubMed: 16683761] 82. Dunn AY, Melville MW, Frydman J. J Struct Biol. 2001; 135(2):176-184. [PubMed: 11580267] 83. Morimoto RI. Genes Dev. 2008; 22(11):1427-1438. [PubMed: 18519635]

84. Muchowski PJ, Wacker JL. Nat Rev Neurosci. 2005; 6(1):11-22. [PubMed: 15611723]

85. Spiess C, Meyer AS, Reissmann S, Frydman J. Trends Cell Biol. 2004; 14(11):598-604. [PubMed: $15519848]$

86. Broadley SA, Hartl FU. FEBS Lett. 2009; 583(16):2647-2653. [PubMed: 19393652]

87. Albanese V, Yam AY, Baughman J, Parnot C, Frydman J. Cell. 2006; 124(1):75-88. [PubMed: 16413483]

88. Thulasiraman V, Yang CF, Frydman J. EMBO J. 1999; 18(1):85-95. [PubMed: 9878053]

89. Dekker C, Stirling PC, McCormack EA, Filmore H, Paul A, Brost RL, Costanzo M, Boone C, Leroux MR, Willison KR. EMBO J. 2008; 27(13):1827-1839. [PubMed: 18511909]

90. Kaverina I, Krylyshkina O, Beningo K, Anderson K, Wang YL, Small JV. J Cell Sci. 2002; 115(Pt 11):2283-2291. [PubMed: 12006613]

91. Goldbaum O, Riedel M, Stahnke T, Richter-Landsberg C. Glia. 2009; 57(14):1566-1577. [PubMed: 19330846] 
92. Bechtold DA, Brown IR. Neurochem Res. 2003; 28(8):1163-1173. [PubMed: 12834255]

93. Fisher BR, Heredia DJ, Brown KM. Teratog Carcinog Mutagen. 1996; 16(1):49-64. [PubMed: 8792533]

94. Fisher BR, Heredia DJ, Brown KM. Teratology. 1995; 52(2):90-100. [PubMed: 8588186]

95. Hartl FU, Hayer-Hartl M. Nat Struct Mol Biol. 2009; 16(6):574-581. [PubMed: 19491934]

96. Cuellar J, Martin-Benito J, Scheres SH, Sousa R, Moro F, Lopez-Vinas E, Gomez-Puertas P, Muga A, Carrascosa JL, Valpuesta JM. Nat Struct Mol Biol. 2008; 15(8):858-864. [PubMed: 18660820]

97. Hut HM, Kampinga HH, Sibon OC. Mol Biol Cell. 2005; 16(8):3776-3785. [PubMed: 15930131]

98. Lange BM, Bachi A, Wilm M, Gonzalez C. EMBO J. 2000; 19(6):1252-1262. [PubMed: 10716925]

99. Weis F, Moullintraffort L, Heichette C, Chretien D, Garnier C. J Biol Chem. 2010; 285(13):95259534. [PubMed: 20110359]

100. Zhai Y, Kronebusch PJ, Simon PM, Borisy GG. J Cell Biol. 1996; 135(1):201-214. [PubMed: 8858174]

101. Czar MJ, Welsh MJ, Pratt WB. Eur J Cell Biol. 1996; 70(4):322-330. [PubMed: 8864660]

102. Lee YC, Lai YK. J Cell Biochem. 1995; 57(1):150-162. [PubMed: 7721954]

103. Quinta HR, Maschi D, Gomez-Sanchez C, Piwien-Pilipuk G, Galigniana MD. J Neurochem. 2010; 115(3):716-734. [PubMed: 20796173]

104. Donnelly AC, Mays JR, Burlison JA, Nelson JT, Vielhauer G, Holzbeierlein J, Blagg BS. J Org Chem. 2008; 73(22):8901-8920. [PubMed: 18939877]

105. Csermely P, Schnaider T, Soti C, Prohaszka Z, Nardai G. Pharmacol Ther. 1998; 79(2):129-168. [PubMed: 9749880]

106. Sausville EA, Elsayed Y, Monga M, Kim G. Annu Rev Pharmacol Toxicol. 2003; 43:199-231. [PubMed: 12195027]

107. Neckers L. Trends Mol Med. 2002; 84 Suppl:S55-S61. [PubMed: 11927289]

108. Ding AH, Porteu F, Sanchez E, Nathan CF. Science. 1990; 248(4953):370-372. [PubMed: 1970196]

109. Byrd CA, Bornmann W, Erdjument-Bromage H, Tempst P, Pavletich N, Rosen N, Nathan CF, Ding A. Proc Natl Acad Sci U S A. 1999; 96(10):5645-5650. [PubMed: 10318938]

110. Solit DB, Basso AD, Olshen AB, Scher HI, Rosen N. Cancer Res. 2003; 63(9):2139-2144. [PubMed: 12727831]

111. Basso AD, Solit DB, Chiosis G, Giri B, Tsichlis P, Rosen N. J Biol Chem. 2002; 277(42):3985839866. [PubMed: 12176997]

112. Cheung CH, Cheng L, Chang KY, Chen HH, Chang JY. Front Biosci. 2011; 16:952-961. [PubMed: 21196211]

113. Fulda S, Debatin KM. Oncogene. 2004; 23(40):6702-6711. [PubMed: 15273734]

114. Cheung CH, Chen HH, Kuo CC, Chang CY, Coumar MS, Hsieh HP, Chang JY. Mol Cancer. 2009; 8:43. [PubMed: 19575780]

115. Fortugno P, Beltrami E, Plescia J, Fontana J, Pradhan D, Marchisio PC, Sessa WC, Altieri DC. Proc Natl Acad Sci U S A. 2003; 100(24):13791-13796. [PubMed: 14614132]

116. Cheung CH, Chen HH, Cheng LT, Lyu KW, Kanwar JR, Chang JY. Mol Cancer. 2010; 9:77. [PubMed: 20398291]

117. Sah NK, Khan Z, Khan GJ, Bisen PS. Cancer Lett. 2006; 244(2):164-171. [PubMed: 16621243]

118. Grantham J, Brackley KI, Willison KR. Exp Cell Res. 2006; 312(12):2309-2324. [PubMed: 16765944]

119. Brackley KI, Grantham J. Exp Cell Res. 2010; 316(4):543-553. [PubMed: 19913534]

120. Hotulainen P, Paunola E, Vartiainen MK, Lappalainen P. Mol Biol Cell. 2005; 16(2):649-664. [PubMed: 15548599]

121. Brackley KI, Grantham J. Cell Stress Chaperones. 2011; 16(2):173-179. [PubMed: 20890741]

122. Van den Abbeele A, De Corte V, Van Impe K, Bruyneel E, Boucherie C, Bracke M, Vandekerckhove J, Gettemans J. Cancer Lett. 2007; 255(1):57-70. [PubMed: 17493746] 
123. Lin YF, Tsai WP, Liu HG, Liang PH. Cancer Res. 2009; 69(17):6879-6888. [PubMed: 19690144]

124. Feldman DE, Spiess C, Howard DE, Frydman J. Mol Cell. 2003; 12(5):1213-1224. [PubMed: 14636579]

125. Bivi N, Romanello M, Harrison R, Clarke I, Hoyle DC, Moro L, Ortolani F, Bonetti A, Quadrifoglio F, Tell G, Delneri D. Genome Biol. 2009; 10(9):R93. [PubMed: 19744312]

126. Jo H, Loison F, Hattori H, Silberstein LE, Yu H, Luo HR. PLoS One. 2010; 5(4):e10318. [PubMed: 20428237]

127. Meierhofer D, Wang X, Huang L, Kaiser P. J Proteome Res. 2008; 7(10):4566-4576. [PubMed: 18781797]

128. Sellin ME, Holmfeldt P, Stenmark S, Gullberg M. Exp Cell Res. 2008; 314(6):1367-1377. [PubMed: 18262179]

129. Burke D, Gasdaska P, Hartwell L. Mol Cell Biol. 1989; 9(3):1049-1059. [PubMed: 2657385]

130. Tam S, Geller R, Spiess C, Frydman J. Nat Cell Biol. 2006; 8(10):1155-1162. [PubMed: 16980959]

131. Kubota S, Kubota H, Nagata K. Proc Natl Acad Sci U S A. 2006; 103(22):8360-8365. [PubMed: 16717193]

132. Buee L, Bussiere T, Buee-Scherrer V, Delacourte A, Hof PR. Brain Res Brain Res Rev. 2000; 33(1):95-130. [PubMed: 10967355]

133. Salminen A, Ojala J, Kaarniranta K, Hiltunen M, Soininen H. Prog Neurobiol. 2011; 93(1):99_ 110. [PubMed: 21056617]

134. Guillozet-Bongaarts AL, Garcia-Sierra F, Reynolds MR, Horowitz PM, Fu Y, Wang T, Cahill ME, Bigio EH, Berry RW, Binder LI. Neurobiol Aging. 2005; 26(7):1015-1022. [PubMed: 15748781]

135. Weaver CL, Espinoza M, Kress Y, Davies P. Neurobiol Aging. 2000; 21(5):719-727. [PubMed: 11016541]

136. Chambraud B, Sardin E, Giustiniani J, Dounane O, Schumacher M, Goedert M, Baulieu EE. Proc Natl Acad Sci U S A. 2010; 107(6):2658-2663. [PubMed: 20133804]

137. Jinwal UK, Koren J 3rd, Borysov SI, Schmid AB, Abisambra JF, Blair LJ, Johnson AG, Jones JR, Shults CL, O'Leary JC 3rd, Jin Y, Buchner J, Cox MB, Dickey CA. J Neurosci. 2010; 30(2):591599. [PubMed: 20071522]

138. Gong CX, Liu F, Wu G, Rossie S, Wegiel J, Li L, Grundke-Iqbal I, Iqbal K. J Neurochem. 2004; 88(2):298-310. [PubMed: 14690518]

139. Liu F, Iqbal K, Grundke-Iqbal I, Rossie S, Gong CX. J Biol Chem. 2005; 280(3):1790-1796. [PubMed: 15546861]

140. Vaughan CK, Mollapour M, Smith JR, Truman A, Hu B, Good VM, Panaretou B, Neckers L, Clarke PA, Workman P, Piper PW, Prodromou C, Pearl LH. Mol Cell. 2008; 31(6):886-895. [PubMed: 18922470]

141. Luo W, Dou F, Rodina A, Chip S, Kim J, Zhao Q, Moulick K, Aguirre J, Wu N, Greengard P, Chiosis G. Proc Natl Acad Sci U S A. 2007; 104(22):9511-9516. [PubMed: 17517623]

142. Shimura H, Miura-Shimura Y, Kosik KS. J Biol Chem. 2004; 279(17):17957-17962. [PubMed: 14963027]

143. Dabir DV, Trojanowski JQ, Richter-Landsberg C, Lee VM, Forman MS. Am J Pathol. 2004; 164(1):155-166. [PubMed: 14695329]

144. Bjorkdahl C, Sjogren MJ, Zhou X, Concha H, Avila J, Winblad B, Pei JJ. J Neurosci Res. 2008; 86(6):1343-1352. [PubMed: 18061943]

145. Sahara N, Maeda S, Yoshiike Y, Mizoroki T, Yamashita S, Murayama M, Park JM, Saito Y, Murayama S, Takashima A. J Neurosci Res. 2007; 85(14):3098-3108. [PubMed: 17628496]

146. Dou F, Netzer WJ, Tanemura K, Li F, Hartl FU, Takashima A, Gouras GK, Greengard P, Xu H. Proc Natl Acad Sci U S A. 2003; 100(2):721-726. [PubMed: 12522269]

147. Elliott E, Tsvetkov P, Ginzburg I. J Biol Chem. 2007; 282(51):37276-37284. [PubMed: 17954934] 
148. Dickey CA, Kamal A, Lundgren K, Klosak N, Bailey RM, Dunmore J, Ash P, Shoraka S, Zlatkovic J, Eckman CB, Patterson C, Dickson DW, Nahman NS Jr. Hutton M, Burrows F, Petrucelli L. J Clin Invest. 2007; 117(3):648-658. [PubMed: 17304350]

149. Czar MJ, Lyons RH, Welsh MJ, Renoir JM, Pratt WB. Mol Endocrinol. 1995; 9(11):1549-1560. [PubMed: 8584032]

150. Silverstein AM, Galigniana MD, Kanelakis KC, Radanyi C, Renoir JM, Pratt WB. J Biol Chem. 1999; 274(52):36980-36986. [PubMed: 10601253]

151. Elbi C, Walker DA, Lewis M, Romero G, Sullivan WP, Toft DO, Hager GL, DeFranco DB. Sci STKE. 2004; 2004(238):110.

152. Gross KL, Westberry JM, Hubler TR, Sadosky PW, Singh RJ, Taylor RL, Scammell JG. Comp Med. 2008; 58(4):381-388. [PubMed: 18724781]

153. Banerjee A, Periyasamy S, Wolf IM, Hinds TD Jr. Yong W, Shou W, Sanchez ER. Biochemistry. 2008; 47(39):10471-10480. [PubMed: 18771283]

154. Gold BG, Villafranca JE. Curr Top Med Chem. 2003; 3(12):1368-1375. [PubMed: 12871168]

155. Gold BG, Densmore V, Shou W, Matzuk MM, Gordon HS. J Pharmacol Exp Ther. 1999; 289(3): 1202-1210. [PubMed: 10336507]

156. Wright NT, Cannon BR, Zimmer DB, Weber DJ. Curr Chem Biol. 2009; 3(2):138-145. [PubMed: 19890475]

157. Shimamoto S, Kubota Y, Tokumitsu H, Kobayashi R. FEBS Lett. 2010; 584(6):1119-1125. [PubMed: 20188096]

158. Shim S, Yuan JP, Kim JY, Zeng W, Huang G, Milshteyn A, Kern D, Muallem S, Ming GL, Worley PF. Neuron. 2009; 64(4):471-483. [PubMed: 19945390]

159. Hinds TD Jr. Sanchez ER. Int J Biochem Cell Biol. 2008; 40(11):2358-2362. [PubMed: 17951098]

160. Silverstein AM, Galigniana MD, Chen MS, Owens-Grillo JK, Chinkers M, Pratt WB. J Biol Chem. 1997; 272(26):16224-16230. [PubMed: 9195923]

161. Galigniana MD, Housley PR, DeFranco DB, Pratt WB. J Biol Chem. 1999; 274(23):1622216227. [PubMed: 10347177]

162. Galigniana MD, Harrell JM, Housley PR, Patterson C, Fisher SK, Pratt WB. Brain Res Mol Brain Res. 2004; 123(1-2):27-36. [PubMed: 15046863]

163. Liu F, Grundke-Iqbal I, Iqbal K, Gong CX. Eur J Neurosci. 2005; 22(8):1942-1950. [PubMed: 16262633]

164. Hammond JW, Cai D, Verhey KJ. Curr Opin Cell Biol. 2008; 20(1):71-76. [PubMed: 18226514]

165. Reed NA, Cai D, Blasius TL, Jih GT, Meyhofer E, Gaertig J, Verhey KJ. Curr Biol. 2006; 16(21): 2166-2172. [PubMed: 17084703]

166. Liao G, Gundersen GG. J Biol Chem. 1998; 273(16):9797-9803. [PubMed: 9545318]

167. Verhey KJ, Gaertig J. Cell Cycle. 2007; 6(17):2152-2160. [PubMed: 17786050]

168. Duan J, Gorovsky MA. Curr Biol. 2002; 12(4):313-316. [PubMed: 11864572]

169. Westermann S, Weber K. Nat Rev Mol Cell Biol. 2003; 4(12):938-947. [PubMed: 14685172]

170. Zilberman Y, Ballestrem C, Carramusa L, Mazitschek R, Khochbin S, Bershadsky A. J Cell Sci. 2009; 122(Pt 19):3531-3541. [PubMed: 19737819]

171. Creppe C, Malinouskaya L, Volvert ML, Gillard M, Close P, Malaise O, Laguesse S, Cornez I, Rahmouni S, Ormenese S, Belachew S, Malgrange B, Chapelle JP, Siebenlist U, Moonen G, Chariot A, Nguyen L. Cell. 2009; 136(3):551-564. [PubMed: 19185337]

172. Kovacs JJ, Murphy PJ, Gaillard S, Zhao X, Wu JT, Nicchitta CV, Yoshida M, Toft DO, Pratt WB, Yao TP. Mol Cell. 2005; 18(5):601-607. [PubMed: 15916966]

173. Murphy PJ, Morishima Y, Kovacs JJ, Yao TP, Pratt WB. J Biol Chem. 2005; 280(40):3379233799. [PubMed: 16087666]

174. Ammer AG, Weed SA. Cell Motil Cytoskeleton. 2008; 65(9):687-707. [PubMed: 18615630]

175. Park SJ, Suetsugu S, Takenawa T. EMBO J. 2005; 24(8):1557-1570. [PubMed: 15791211]

176. Gao YS, Hubbert CC, Lu J, Lee YS, Lee JY, Yao TP. Mol Cell Biol. 2007; 27(24):8637-8647. [PubMed: 17938201] 


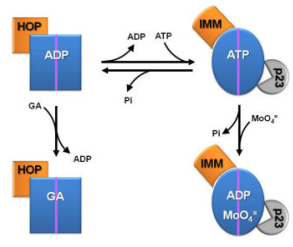

Figure 1. Model of the ATP cycle of Hsp90 and its interaction with Hop, IMMs and p23 The reversible exchange of ADP by ATP induces a conformational change in Hsp90 dimers that locks ATP into its binding site. This conformation state is stablized by the cochaperone p23, and Hsp90 recruits TPR-domain immunophilins (IMMs) and shows optimal chaperoning properties to interact with client proteins. Hsp90 returns to the ADP-bound conformation due to its intrinsic ATPase activity. Molybdate traps Hsp90 in its active conformation because the $\gamma$-phosphate is replaced by the oxyanion and prevent ADP dissociation (generating and ATP-like state). On the other hand, the benzoquinone ansamycin antibiotic geldanamycin (GA) stabilizes the ADP-bound state of Hsp90 favoring its interaction with the TPR-domain cochaperone Hop rather than with IMMs. 


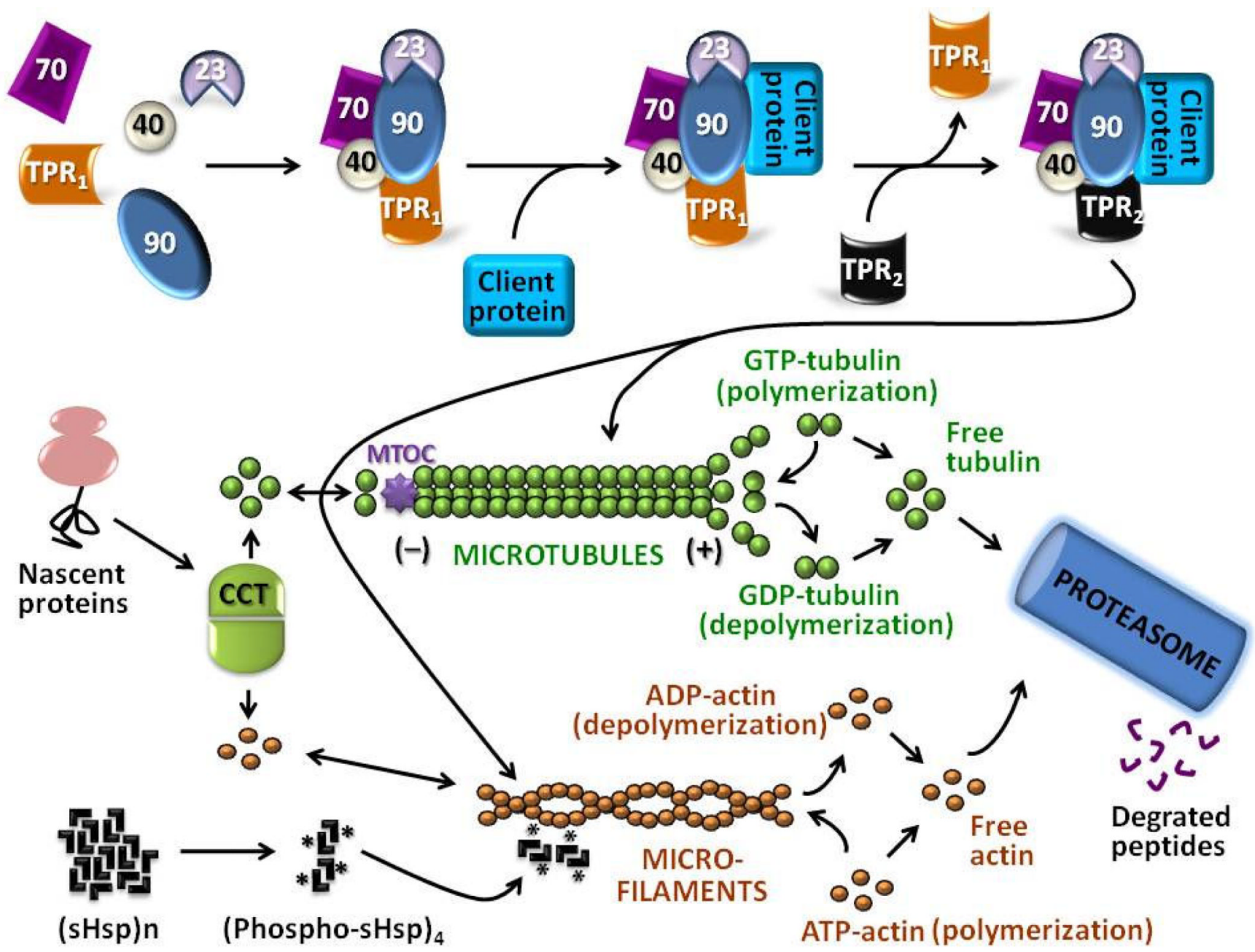

Figure 2. Cytoskeleton proteostasis is managed by molecular chaperones

Proteins emerging from ribosomes can be delivered to the CCT/TRiC chaperone machinery for correct folding. Those proteins that cannot be shaped properly are targeted to degradation. Based on their abundance, actin and tubulin probably occupy a substantial proportion of CCT/TRiC complexes at any given time. Native actin and tubulin assemble into microfilaments and microtubules in a nucleotide-regulated manner (ADP/ATP and GDP/GTP, respectively) with the additional assistance of other factors (not depicted here for simplicity), whereas free monomers o dimers can be targeted to proteasome degradation. Oligomeryzed small heat-shock proteins (sHsp) n such as Hsp25/Hsp27 can be phosphorylated (asterisks) and form tetrameric structures (Phospho-sHsp) 4 able to stabilize filaments, in particular when the cells are exposed to stress. In turn, the soluble Hsp90-based heterocomplex matures in the cytosol (top of the figure) by assembling Hsp90 with Hsp70, Hsp40, p23 and a TPR-domain protein $\left(\mathrm{TPR}_{1}\right)$ that may represent the need of Hop for priming the complex. This original heterocomplex may undergo further modifications by exchanging the TPR-domain protein, for example, Hop (represented by $\mathrm{TPR}_{1}$ in the scheme) is replaced by a high molecular weight IMM $\left(\mathrm{TPR}_{2}\right)$. The 'mature' heterocomplex stabilizes and also provides gain-of-function properties to several client proteins that may remain soluble or can interact with the cytoskeleton network. It should be pointed out that even the proteasome are ribosomes are also assisted by a complex of chaperones (not depicted). 

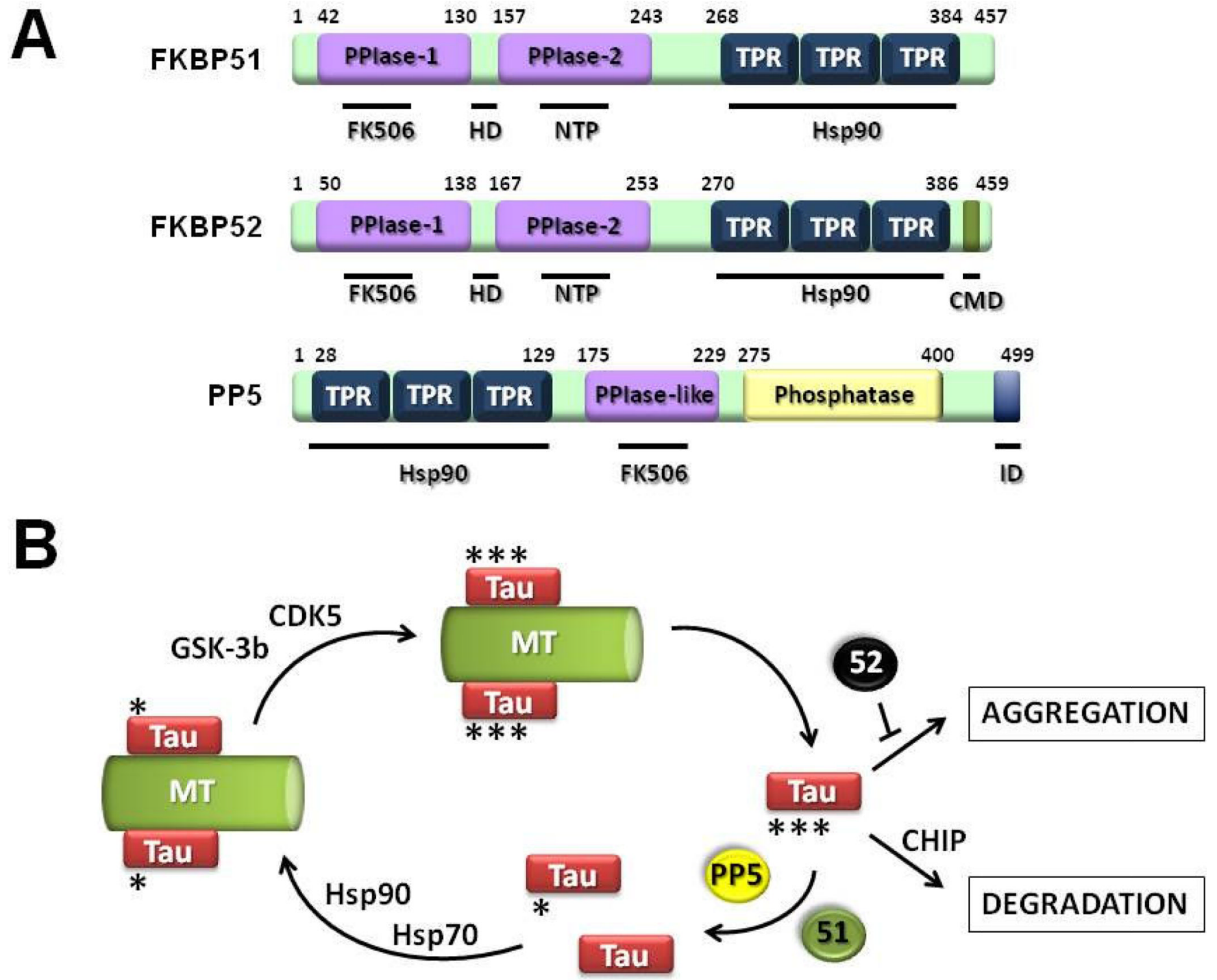

Figure 3. Regulation of the Tau-microtubule interaction

(A) Schematic representation of the structural domains of the high molecular weight immunophilins FKBP51, FKBP52 and PP5 involved in Tau regulation. TPR,

tetratricopeptide repeat domain or Hsp90-interacting domain; FK506, macrolide binding site to the PPIase-1 domain; $H D$, hinge domain (reach in polar amino acids complementary to the nuclear localization signal 1 of steroid receptors); NTP, nucleotide binding domain; $C M D$, calmodulin binding domain; $I D$, inhibitory domain. (B) Tau is phosphorylated (asterisks) in Ser and Thr residues by GSK-3b or CDK5 generating a number phosphoisoforms. Accumulation of misfolded phospho-Tau (toxic) generates aggregates as a protective response, an event that requires Hsp90 and Hsp70 and is counteracted by overexpression of FKBP52 and the Hsp90 inhibitor geldanamycin. The chaperone heterocomplex can refold Tau, whose dephosphorylated isoforms are reincorporated to microtubules. The IMM-like Ser/Thr-protein phosphatase PP5 plays a key role in this regard and is assisted by FKBP51, an IMM that enhances Tau dephosphorylation and its recycling in a PPIase-dependent manner [137]. Therefore, deficiencies in the isomerase activity of FKBP51 or in the dephosphorylation step can cause the accumulation of phosphorylated Tau 
protein followed by aggregation. The TPR-domain protein CHIP (C terminus of Hsc70interacting protein) favors Tau polyubiquitination and its proteasomal degradation. 

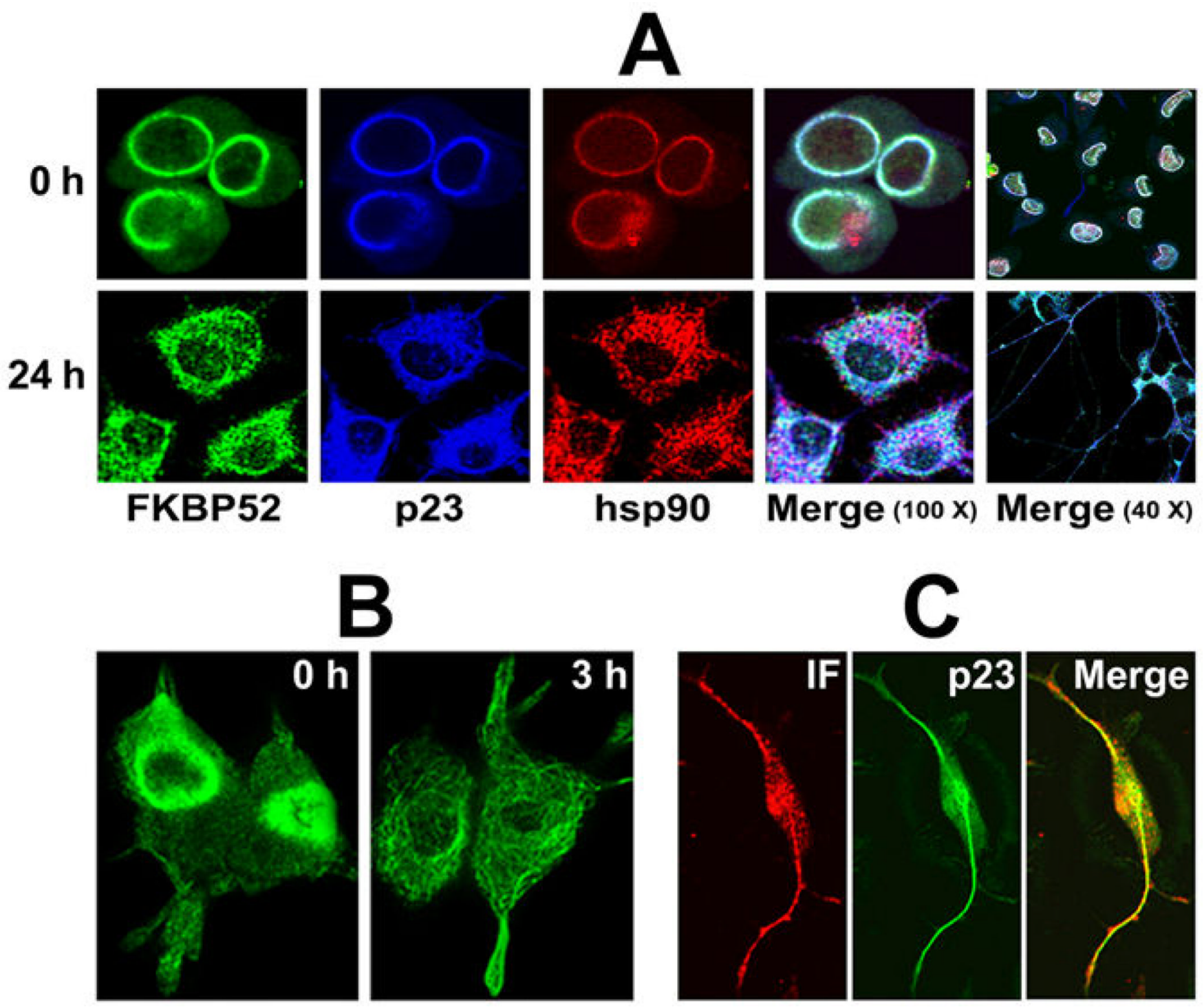

Figure 4. Subcellular redistribution of chaperones and cytoskeleton rearrangement during neuronal differentiation

(A) Images by confocal microscopy of embryonic hippocampal neurons prior and $24 \mathrm{~h}$ after treatment with $1 \mu \mathrm{M}$ FK506. Image on the right hand shows a wider field. (B) Microtubules reorganize after $3 \mathrm{~h}$ of differentiation. (C) Intermediate filaments (IF) of FK506differentiated neurons recruit the Hsp90-cochaperone $\mathrm{p} 23$. 